\title{
The distribution and abundance of chironomids in high-latitude Eurasian lakes with respect to temperature and continentality: development and application of new chironomid-based climate-inference models in northern Russia
}

\author{
A.E. Self ${ }^{a, b}, *$ S.J. Brooks ${ }^{a}$, H.J.B. Birks ${ }^{\text {b,c,d }}$, L. Nazarova ${ }^{e}$, D. Porinchu ${ }^{f}$, A. Odland ${ }^{g}$, H. Yang $^{b}$, V.J. Jones ${ }^{b}$ \\ a Department of Entomology, Natural History Museum, Cromwell Road, London SW7 5BD, UK \\ ${ }^{\mathrm{b}}$ Environmental Change Research Centre, Department of Geography, University College London, Gower Street, London WC1E 6BT, UK \\ ${ }^{c}$ Department of Biology, Bjerknes Centre for Climate Research, University of Bergen, P.O. Box 7803, N-5020 Bergen, Norway \\ ${ }^{\mathrm{d}}$ School of Geography and the Environment, University of Oxford, South Parks Road, Oxford OX1 3QY, UK \\ ${ }^{\mathrm{e}}$ Alfred Wegener Institute for Polar and Marine Research, Telegrafenberg A 43, 14473 Potsdam, Germany \\ ${ }^{\mathrm{f}}$ Department of Geography, The Ohio State University, 1036 Derby Hall, 154 N. Oval Mall, Columbus, OH 43210, USA \\ $\mathrm{g}$ Institute of Environmental Studies, Telemark University College, N-3800 Bø, Norway
}

\section{A R T I C L E I N F O}

\section{Article history:}

Received 10 June 2010

Received in revised form

18 January 2011

Accepted 19 January 2011

Available online $\mathrm{xxx}$

\section{Keywords:}

Chironomids

Palaeolimnology

Russia

Climate change

Transfer function

Continentality

Species responses

WA-PLS

\begin{abstract}
A B S T R A C T
The large landmass of northern Russia has the potential to influence global climate through amplification of climate change. Reconstructing climate in this region over millennial timescales is crucial for understanding the processes that affect the global climate system. Chironomids, preserved in lake sediments, have the potential to produce high resolution, low error, quantitative summer air temperature reconstructions. Canonical correspondence analysis of modern surface sediments from high-latitude lakes, located in northern European Russia and central Siberia, suggests that mean July air temperature is the most significant variable explaining chironomid distribution and abundance. This strong relationship enabled the development of a chironomid-based mean July air temperature-inference model based on 81 lakes and 89 taxa which has a $r_{\text {jack }}^{2}=0.92$ and $\operatorname{RMSEP}=0.89^{\circ} \mathrm{C}$. Comparison of taxon responses to July temperature between this Russian and existing Norwegian data-sets shows that the temperature optima of individual taxa were between 1 and $3{ }^{\circ} \mathrm{C}$ higher in the Russian data regardless of modelling technique. Reconstructions based on fossil assemblages from a Russian tundra lake core (VORK5) using a Norwegian chironomid-based inference model provide mean July air temperature estimates that are $1.0-2.7^{\circ} \mathrm{C}$ colder than from the 81-lake Russian model and are also lower than the instrumental record from a nearby meteorological station. The Norwegian model also did not reconstruct decadal-scale fluctuations in temperature seen in the instrumental record. These observations suggest that chironomid-based inference models should only be applied to sediment cores which have similar climate regimes to the geographic area of the training set. In addition a 149 lake, 120 taxa chironomid-based continentality inference model was also developed from the modern Norwegian and Russian training sets. A 2component WA-PLS model was the minimal adequate model with $r_{\text {jack }}^{2}=0.73$ and RMSEP $=9.9$ using the Gorczynski continentality index. Comparison of reconstructed continentality indices from the tundra lake, VORK5, show close agreement with local instrumental records over the past 70 years and suggest that the model is reliable. Recent warming in the Arctic has been spatially and seasonally heterogeneous; in many areas warming is more pronounced in the spring and autumn leading to a lengthening of the summer, while summer temperatures have remained relatively stable. A continentality inference model has the potential to detect these seasonal changes in climate.
\end{abstract}

๑) 2011 Elsevier Ltd. All rights reserved.

\footnotetext{
* Corresponding author. Department of Entomology, Natural History Museum, Cromwell Road, London SW7 5BD, UK. Tel.: +44 2079425595.

E-mail address: a.self@nhm.ac.uk (A.E. Self).
}

\section{Introduction}

The Arctic is particularly sensitive to perturbations in climate; average arctic temperatures have increased at almost twice the global average rate over the past 100 years and this trend is predicted to continue over the twenty first century (IPCC, 2007). The

0277-3791/\$ - see front matter (c) 2011 Elsevier Ltd. All rights reserved. doi:10.1016/j.quascirev.2011.01.022 
large landmass of northern Eurasia plays an important role in global climate dynamics and in the amplification of climate change by positive feedbacks. For example, enhanced snow pack and permafrost melting increase freshwater discharge from Eurasian rivers and hence heat advection from low latitudes (Peterson et al., 2002; McClelland et al., 2004). The scarcity of observational and proxy records has meant that northern Russia is often poorly represented in the global perspective of climate trends and their effects on ecosystems (for example Smol et al., 2005). However, given its potential as an important driver of global climates, studies of northern Russia are important for understanding the timing and magnitude of past climate change and the mechanisms underlying those changes.

Instrumental climate records in arctic Russia are sparse, of short duration and often intermittent (Rigor et al., 2000). Meteorological stations are often located in the most benign habitats, for example at lower, warmer elevations, which are unrepresentative of the regional climate (Rawlins and Willmott, 2003). Satellite data have become available over recent decades and suggest mean annual temperatures have increased since AD 1981 in some areas of northern Russia whereas other regions have cooled (Comiso, 2003). In the absence of long-term instrumental or satellite data, palaeolimnological techniques can be used to determine whether these regional responses are a persistent feature of Holocene climate change across northern Russia or a short-term non-equilibrium response to present climate forcing.

Subfossil remains of chironomid midge larvae (Insecta, Diptera, Chironomidae) are abundant and well-preserved in lake sediments (Brooks, 2003). Chironomids are sensitive indicators of environmental conditions (Lindegaard, 1995). Their distribution is influenced by many factors including lake trophic status (Brundin, 1958; Wiederholm, 1983), water depth (Heiri, 2004) and oxygen stress (Quinlan and Smol, 2001b). However, the analysis of training sets of present-day assemblages and associated environmental data from lake surface sediments has shown mean summer temperature to be the dominant factor determining chironomid distribution and abundance over wide geographical regions (for example Walker et al., 1991; Brooks and Birks, 2001; Larocque et al., 2001; Barley et al., 2006). The strength of the relationship has enabled the development of quantitative chironomid-based temperature-inference models which have been used to reconstruct past temperatures in many areas of Western Europe and North America (see reviews in Brooks, 2006a,b; Barley et al., 2006), however relatively little data are available from Russia.

Quantitative chironomid-based reconstructions of palaeotemperature have been derived for northern Russia using European training sets. Solovieva et al. (2005) reconstructed mean July air temperatures in north-east European Russia using a chironomid-July air temperature-inference model based on a modern training set of 153 Norwegian lakes (Brooks and Birks, 2001 and unpublished data) supplemented with data from lakes within the study area. The chironomid-temperature-inference model developed for northern Sweden (Larocque et al., 2001) has also been used for temperature reconstructions in the Lena River Delta (Andreev et al., 2004), the Kola Peninsula (Ilyashuk et al., 2005) and Polar Urals (Andreev et al., 2005). However as more easterly sites are investigated the use of these European-based training sets may not be applicable due to the restricted geographic ranges of certain taxa and potential obstacles to dispersal. A number of important taxa in Russian subfossil assemblages, such as Constempellina and Mesocricotopus (Andreev et al., 2005), are absent or poorly represented in the European data-sets leading to poor analogues and potentially unreliable reconstructions for the Russian sequences. Additionally, the selective pressure resulting from the extreme continental climate of central Eurasia, where annual temperatures vary from a winter minimum of $-71.2{ }^{\circ} \mathrm{C}$ to a summer maximum of $38-40^{\circ} \mathrm{C}$ (Nazarova et al., 2008), may elicit physiological or behavioural adaptations in the chironomid fauna or changes in the faunal composition in response to the extreme environment.

The relationship between the distance from the open ocean, climate and vegetation was first recognised by von Humboldt (1827) and the use of continentality indices is well established in agriculture, geography, meteorology and ecology as a means of describing the climate regime, by quantifying the influence of the ocean on the climate. Plant species are often most sensitive to the effects of continentality along their northern limits and Giesecke et al. (2008) used the distribution of temperate tree species in Fennoscandia to develop a pollen-based continentality inference model. Although the influence of continentality has been less well studied in insects than plants a number of studies suggest it may also be important in insect distribution. For example, outbreaks of forest-defoliating insects are more frequent and intense in eastern than western Ukraine (Meshkova, 2002) as the greater continentality of eastern Ukraine results in a more rapid increase in spring air temperature which accelerates larval development. Over the Late Quaternary the climate regime of the Russian Arctic may have changed due to variations in solar radiation, changes in atmospheric circulation around ice sheets or changes in sea level. The latter is particularly important in Siberia where the coastline at the start of the Holocene was approximately $170 \mathrm{~km}$ north of its present location (Bauch et al., 2001) resulting in a more continental environment than at the same latitudes today. Increased continentality caused by eustatically lower sea level has been identified as a potential influence on Holocene tree-line dynamics within this region (MacDonald et al., 2000). Therefore the continentality of a location may have changed whilst the summer temperatures remained unaltered. As chironomids are abundant and widespread throughout the Russian arctic the potential for developing a chironomid-based continentality model was investigated in this study.

In this paper, the environmental factors which influence chironomid distribution and abundance in northern Russia are examined with the aim of developing chironomid-based inference models for climate reconstructions in this climatically sensitive region. The faunal composition and species responses are compared with data from Norway; this is a large data-set of modern chironomid distribution and abundance in surface sediments from 157 high-latitude lakes from Svalbard and mainland Norway (Brooks and Birks, 2001 and unpublished data). In theory combining the data-sets would improve the distribution of lakes along the July temperature gradient and the representation of taxa which are uncommon in the Norwegian fauna but is only justifiable if the chironomid assemblages, and responses to environmental variables, are similar.

There are three main aims:

1. To examine the environmental factors which influence chironomid distribution and abundance in northern Russia and assess whether these vary from the factors affecting the distribution and abundance of chironomids in Norway.

2. To determine whether the Norwegian and Russian training sets could be combined to develop a northern Eurasia training set to reconstruct past climates or whether the training sets should be limited to specific geographic areas.

3. To identify climate variables which have the potential for palaeoenvironmental reconstructions and develop chironomid-based inference models for climate reconstructions in north-east Russia. 


\section{Regional setting}

Surface sediments were collected from 100 lakes in arctic and subarctic Russia between 61 and $72^{\circ} \mathrm{N}$ and $50-132^{\circ} \mathrm{E}$ (Fig. 1). The study sites span major biomes such as the boundaries between the continuous and the discontinuous permafrost zones and from boreal coniferous forests in the south to tundra vegetation in north. Most of the lakes are shallow (mean water depth $4.1 \mathrm{~m}$ ) and remote. The lakes represent a range of different climatic conditions and whilst the physical and chemical characteristics, (e.g. pH, conductivity) are similar for the majority of the lakes, the underlying geology varies. Quaternary deposits are widely distributed throughout the Pechora, Lena, and Yenisey river valleys (Nalvikin, 1973). The lakes in the Komi Republic are formed on a sedimentary sequence of Palaeozoic carbonate and deep marine shale (Lindquist, 1999). The remaining lakes from the Putorana Plateau, the southern Lena Delta and near Vilyuysk, in central Yakutia, lie on the Siberian Traps, a large igneous province extruded in the late Permian ca 240-220 Myrs (Zolotukhin and Almukhamedov, 1988). The altitude of the lakes varies from $2 \mathrm{~m}$ to $805 \mathrm{~m}$ above sea level (a.s.l.). The mean July air temperature ranges from 8.8 to $18.9{ }^{\circ} \mathrm{C}$ and the mean annual precipitation from 240 to $640 \mathrm{~mm}$ (Table 1, Appendix A).

\section{Material and methods}

\subsection{Site selection and field methods}

Surface sediments were collected from 22 lakes in north-east European Russia between AD 1998 and 2001 as part of the EUfunded TUNDRA and SPICE projects as described by Solovieva et al. (2002, 2005) and Sarmaja-Korjonen et al. (2003), 21 lakes from the Lower Lena River as described by Porinchu and Cwynar (2000), and 36 lakes from Central Yakutia by Kumke et al. (2007). Additional surface samples were collected from 10 lakes at Igarka and on the Putorana Plateau in July 2006, 5 lakes near Vorkuta, north-east European Russia in April 2007 and 6 lakes in the Komi Republic, in August 2007. Chironomid assemblage and environmental data from Russia were compared to data from 157 Norwegian lakes from Svalbard and mainland Norway collected between AD 1995 and AD 1999 (Brooks and Birks, 2000, 2001 and unpublished data). The
Table 1

Summary of the environmental data for the 100 Russian lakes (complete data in Appendix A).

\begin{tabular}{|c|c|c|c|c|c|}
\hline & \multicolumn{5}{|c|}{ Russian Lakes (100 lakes) } \\
\hline & Minimum & Mean & Median & Maximum & Std dev \\
\hline Latitude $(\mathrm{N})$ & 61.214 & 66.4951 & 67.1167 & 71.9015 & \\
\hline Longitude (E) & 50.5029 & 99.4822 & 121.6545 & 131.2273 & \\
\hline Altitude (m a.s.l) & 2 & 151 & 111 & 805 & 176 \\
\hline $\begin{array}{l}\text { Distance to } \\
\text { coast }(\mathrm{km})\end{array}$ & 16 & 485 & 503 & 5000 & 566 \\
\hline $\mathrm{pH}$ & 5.14 & 7.7 & 7.5 & 9.92 & 0.89 \\
\hline $\begin{array}{l}\text { Conductivity } \\
\left(\mu \mathrm{S} \mathrm{cm}^{-1}\right)\end{array}$ & 2.4 & 160.1 & 58 & 2980 & 356.4 \\
\hline Water depth (m) & 0.7 & 3.8 & 2.2 & 25 & 4.3 \\
\hline$T_{\text {july }}\left({ }^{\circ} \mathrm{C}\right)$ & 8.8 & 14.5 & 13.4 & 19 & 3.5 \\
\hline$T_{\text {jan }}\left({ }^{\circ} \mathrm{C}\right)$ & -39.4 & -29.7 & -34.4 & -15.5 & 8.8 \\
\hline Continentality Index & 31 & 62 & 58 & 91 & 20 \\
\hline $\begin{array}{l}\text { Mean annual } \\
\text { precipitation (mm) }\end{array}$ & 239 & 364 & 283 & 640 & 121 \\
\hline $\mathrm{Cl}^{-}\left(\mu \mathrm{eq} \mathrm{l}^{-1}\right)$ & 2 & 141 & 30 & 5896 & 621 \\
\hline $\mathrm{SO}_{4}^{2-}\left(\mu \mathrm{eq} \mathrm{l}^{-1}\right)$ & 1 & 46 & 25 & 760 & 90 \\
\hline $\mathrm{Ca}^{2+}\left(\mu \mathrm{eq} \mathrm{I} \mathrm{l}^{-1}\right)$ & 18 & 518 & 344 & 1921 & 462 \\
\hline $\mathrm{Mg}^{2+}\left(\mu \mathrm{eq} \mathrm{I}^{-1}\right)$ & 15 & 849 & 157 & 17270 & 2479 \\
\hline $\mathrm{Na}^{+}\left(\mu \mathrm{eq} \mathrm{l}^{-1}\right)$ & 10 & 579 & 84 & 25141 & 2666 \\
\hline
\end{tabular}

sampling methods from all the locations are broadly similar to the following method. Sediment cores were collected from the deepest point of each lake using an $80 \mathrm{~mm}$ diameter HON-Kajak corer (Renberg, 1991) with a $0.5 \mathrm{~m}$ Perspex coring tube. Cores were extruded in the field at $0.25-1.0 \mathrm{~cm}$ intervals. For the palaeolimnological study a short core from an unnamed tundra lake, coded VORK5 $\left(67.856972^{\circ} \mathrm{N}, 59.025722^{\circ} \mathrm{E}\right)$ (Fig. 1) was subsampled at $0.5 \mathrm{~cm}$ intervals from 0 to $5 \mathrm{~cm}$ depth, then at $1 \mathrm{~cm}$ intervals to $19 \mathrm{~cm}$ depth. Samples were stored in whirl-pak bags and kept cool and dark in the field prior to storage at $4{ }^{\circ} \mathrm{C}$. The conductivity and $\mathrm{pH}$ of the lakes were measured in the field using portable meters.

\subsection{Laboratory and desktop methods}

\subsubsection{Chironomid analyses}

Sediment samples for subfossil chironomid analysis were prepared using standard methods. Wet sediments were deflocculated in $10 \% \mathrm{KOH}$ at $70{ }^{\circ} \mathrm{C}$ for 5 min then left to stand in hot water for

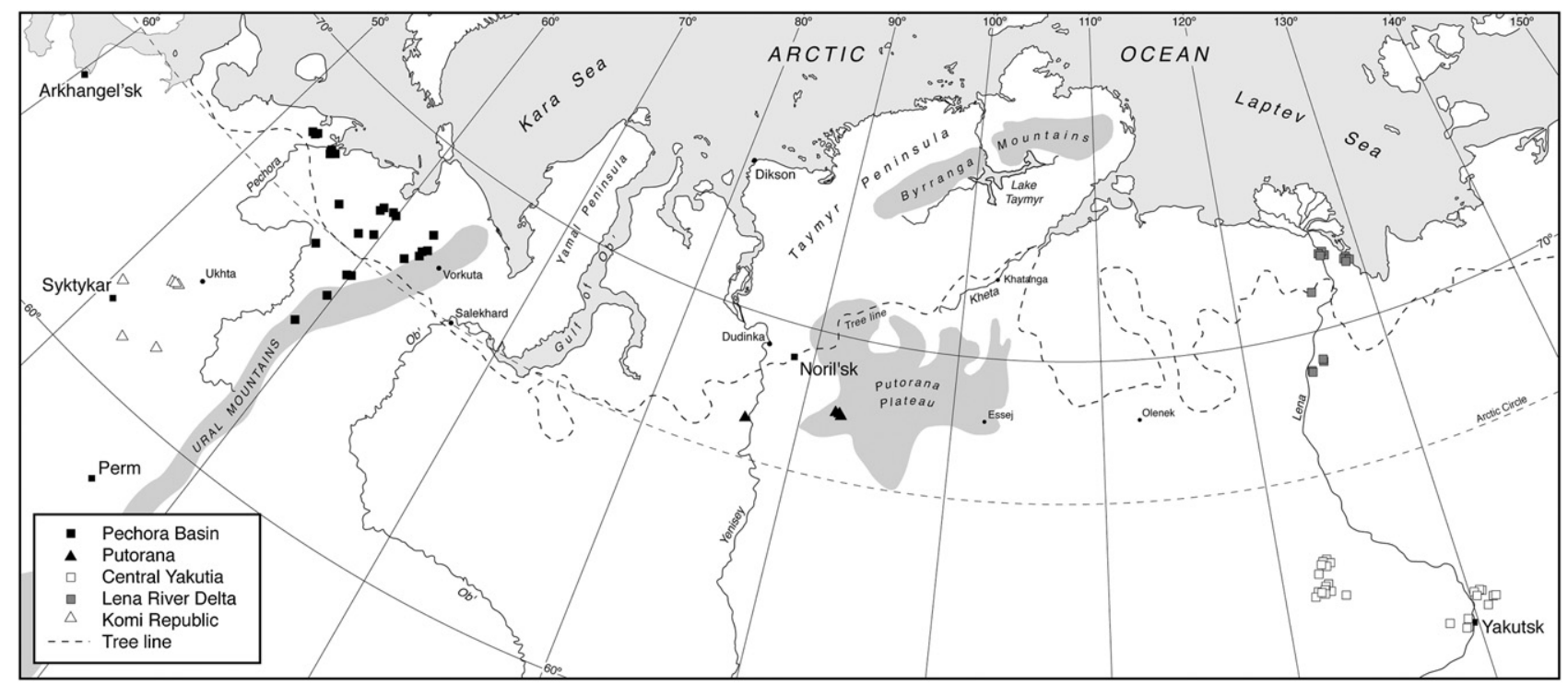

Fig. 1. Map of north-east Russia showing the location of the sampled lakes. 
20 min (Brooks and Birks, 2000). Samples were washed through 212 and $90 \mu \mathrm{m}$ sieves and the re-suspended sediment sorted in a grooved Bogorov tray using a dissecting microscope at $\times 25$ magnification. Head capsules were separated and mounted in Euparal ${ }^{\circledR}$ mounting medium after progressive dehydration in $80 \%$ and $100 \%$ ethanol. Chironomids were identified with reference to Wiederholm (1983), Schmid (1993), Makarchenko and Makarchenko (1999), Rieradevall and Brooks (2001), Brooks et al. (2007) and the national Chironomidae collection at the Natural History Museum, London, UK. The subfossil assemblage was determined in the uppermost $0-1 \mathrm{~cm}$ for the training-set lakes. Between 50 and 560 head capsules were identified from the majority of surface sediments. However only 36-49 head capsules were isolated from seven high-latitude lakes, but the low taxonomic diversity of these assemblages suggests these abundances are acceptable for inclusion in the training set (Quinlan and Smol, 2001a). Between 51 and 194 head capsules were identified from the VORK5 sediment core.

\subsubsection{Water chemistry analyses}

Water samples from Putorana and north-east European Russia were analysed for major cations and anions at the Komi Science Centre, Syktyvkatr, Russia. Sodium $\left(\mathrm{Na}^{+}\right)$and potassium $\left(\mathrm{K}^{+}\right)$were determined by flame emission and magnesium $\left(\mathrm{Mg}^{2+}\right)$ and calcium $\left(\mathrm{Ca}^{2+}\right)$ by atomic absorption spectroscopy. Nitrate $\left(\mathrm{NO}_{3}^{-}\right)$concentrations were determined colorimetrically by cadmium reduction. Sulphate $\left(\mathrm{SO}_{4}^{2-}\right)$ was analysed photomerically and chloride $\left(\mathrm{Cl}^{-}\right)$ determined by potentiomeric titration. Analysis of total phosphorus $\left(P_{\text {tot }}\right)$ in unfiltered water followed Murphy and Riley (1962). Analyses of water samples from Central Yakutia are described by Kumke et al. (2007) and from the Lena Delta by Duff et al. (1998).

\subsubsection{Chronology}

The VORK5 sediment core was dated using ${ }^{210} \mathrm{~Pb}$ and ${ }^{137} \mathrm{Cs}$ at the Bloomsbury Environmental Isotope Facility, UCL. Subsamples from the sediment cores were analysed for ${ }^{210} \mathrm{~Pb},{ }^{226} \mathrm{Ra},{ }^{137} \mathrm{Cs}$ and ${ }^{241} \mathrm{Am}$ by direct gamma assay using an ORTEC HPGe GWL series well-type coaxial low background intrinsic germanium detector. ${ }^{210} \mathrm{~Pb}$ was determined via its gamma emissions at $46.5 \mathrm{keV}$, and ${ }^{226}$ Ra by the $295 \mathrm{keV}$ and $352 \mathrm{keV}$ gamma rays emitted by its daughter isotope ${ }^{214} \mathrm{~Pb}$ following 3 weeks storage in sealed containers to allow radioactive equilibration. ${ }^{137} \mathrm{Cs}$ and ${ }^{241} \mathrm{Am}$ were measured by their emissions at $662 \mathrm{keV}$ and $59.5 \mathrm{keV}$ (Appleby et al., 1986). Radiometric dates were calculated using the CRS ${ }^{210} \mathrm{~Pb}$ dating models (Appleby, 2001) and corrected by the AD 1963 depths determined from the ${ }^{137} \mathrm{Cs}$ and ${ }^{241} \mathrm{Am}$ stratigraphic records.

\subsubsection{Modern climate and derivation of climate variables}

Previous studies suggest that chironomid abundance and distribution are strongly influenced by mean air temperatures of the warmest summer month (e.g. Brooks, 2003, 2006b). Within the study area, July is the warmest month and mean July air temperature is included as an environmental variable. It was estimated for each lake by spatial interpolation of meteorological records from the three nearest weather stations, corrected for altitude. Sampling took place over a 9 year period in north-east European Russia and records from Syktyvkar suggest July air temperatures increased by $0.5^{\circ} \mathrm{C}$ during the period 1977-2006 compared with 1968-97. Therefore mean July air temperatures were estimated from the instrumental data for the 30 years preceding sampling. Gorczynski (1920) derived a continentality index in which the annual difference in temperature is divided by the sine of latitude. Latitude is included as a parameter as solar radiation varies greatly with latitude. However near the equator, the sine of latitude approaches zero resulting in extremely high continentality indices, so later modifications of the index include the addition of constants (for example Grieser et al., 2006). The Grieser et al. (2006) modification of the Gorczynski's index $(\mathrm{CI})$ was used in this study as it is easily computed and applicable to high latitudes:

$\mathrm{CI}=1.7(A / \sin \phi)-20.4$

where $A$ is the annual range of average monthly temperatures in ${ }^{\circ} \mathrm{C}$ and $\varphi$ the latitude of the lake. Within the Russian study area the annual temperature range was based on mean July and January temperatures. CI values ranged from 0 to 29 in the Norwegian dataset and 31-91 in the 100-lake Russian data-set. Mean annual and summer (JJA) precipitation were estimated, for the 30-year period prior to sampling, from monthly observations in the Global Precipitation Climatology Centre (GPCC) database version 3, based on $0.5^{\circ}$ grid intervals (Rudolf et al., 2003).

\subsubsection{Numerical methods}

The major cation and anion concentrations were strongly skewed and were therefore log transformed to normalise their distribution and to stabilise their variances (Birks, 1998). Detrended correspondence analysis (DCA), with detrending by segments, was used to assess the most appropriate numerical technique for further analyses of the chironomid data. Canonical correspondence analysis (CCA) was used to explore the relationship between the chironomid assemblages and the environmental variables. Several of the environmental variables were strongly correlated, and variables with the highest variance inflation factors (VIFs) were sequentially removed from the CCA until the VIFs were less than 20. Significant environmental variables were identified by forward selection and tested using a Monte Carlo permutation test (499 unrestricted permutations). Variables were considered significant if $p<0.05$. CCAs were then run with each forward-selected variable individually. In this analysis, the ratio of the first constrained eigenvalue $\left(\lambda_{1}\right)$ to the second unconstrained eigenvalue $\left(\lambda_{2}\right)$ indicates the potential significance of the variable in explaining the cumulative variance in the taxon data. Inference models derived from explanatory variables with high ratios are therefore likely to have greater predictive power. Both DCA and CCA were performed using CANOCO 4.5 (ter Braak and Šmilauer, 2002) and in both analyses percentage species abundance data were square-root transformed and rare taxa down-weighted.

Two-way indicator species analysis (TWINSPAN) was undertaken using TWINSPAN for Windows version 2.3 (Hill and Šmilauer, 2005). TWINSPAN pseudospecies cut levels were set at $0,2,5,10$ and $20 \%$ to allow differences in taxon abundance to influence classification. The response of individual taxa to specific environmental variables was evaluated by fitting Huisman, Olff and Fresco (HOF) models (Oksanen and Minchin, 2002). These are a series of hierarchical models which are used to describe species responses to environmental variables. Temperature optima of taxa with more than 10 occurrences in both the Norwegian and Russian data-sets were estimated by Gaussian logit regression (GLR). Gaussian response curves were fitted to the data using the program GLR (Version 1.1, Juggins, 1994). The weighted averaging (WA) temperature optimum of each taxon was estimated using C2 (Juggins, 2005). General linear models (GLM) and general additive models (GAM), based on presence-absence data, were developed for taxa with more than 10 occurrences in both the Norwegian and Russian data-sets from the subset using R software ( $\mathrm{R}$ Development Core Team, 2004). Models were fitted using the mgcv package for $R$, version 1.3-24 (Wood, 2007) and the statistical significance of additional parameters was tested using the Akiake Information Criterion (AIC) and Bayes Information Criterion (BIC).

The 100-lake Russian and 157-lake Norwegian data-sets were analysed to examine the relationship between the environmental 
variables, including mean July air temperature and continentality, and chironomid distribution and abundance. Nineteen lakes with extremes of conductivity, $\mathrm{pH}$ or TP (total phosphorus) were removed to produce a second Russian 81-lake data-set with a more even distribution of lakes along the environmental gradients. A summary of the environmental variables in the 81-lake Russian data-set is given in Table 2 and the Norwegian data-set in Table 3. Chironomid-based temperature-inference models were developed from all three data-sets using weighted averaging (WA) and weighted averaging partial least squares (WA-PLS) methods (ter Braak and Looman, 1986; ter Braak and Juggins, 1993) using the program C2 version 1.4.3 (Juggins, 2005). The performance of the models and optimal number of components in the transfer function were assessed using leave-one-out, jack-knifed crossvalidation.

To explore the relationship between chironomid distribution and continentality the 100-lake Russian data-set was combined with the Norwegian training set compiled by Brooks and Birks (2000, 2001) and unpublished data. Mean July air temperature is the main factor influencing the distribution of chironomids. Therefore to minimise the risk of wrongly attributing a temperature-driven response to continentality a subset of 149 lakes were selected from the Norwegian and Russian lakes. Lakes for inclusion were selected by stratified sampling; lakes were stratified by mean July temperature (at $0.5^{\circ} \mathrm{C}$ intervals), then continentality at $1 \mathrm{CI}$ intervals and finally by geographical location (longitude and latitude). If more that one lake from a similar location had the same mean July air temperature and same $\mathrm{CI}$, a single representative lake was chosen by random selection. In the combined data-set the two extremes of the temperature gradient were restricted to a narrow range of continentality indices, the warmest lakes $\left(18-18.9^{\circ} \mathrm{C}\right)$ were located in central Yakutia with extremely high continentality and the coldest lakes $\left(3.5-6.3^{\circ} \mathrm{C}\right)$ in Svalbard have very low CIs of 10-15 so these two extremes were excluded from the continentality data-set by the stratification. The stratification process followed by selection of a single lake will minimise the risk of spatial autocorrelation and produce a data-set in which lakes with mean July air temperatures of $8-16^{\circ} \mathrm{C}$ have a range of continentality indices (from 0 to 70 ). A summary of the environmental variables for this 149 Norwegian-Russian lake data-set is given in Table 4. A chironomid-based continentality inference model was produced and the performance evaluated as described for the temperature models.

Table 2

Summary of environmental data for the subset of 81 Russian lakes.

\begin{tabular}{|c|c|c|c|c|c|}
\hline & \multicolumn{5}{|c|}{ Russian lakes (81 lakes) } \\
\hline & Minimum & Mean & Median & Maximum & Std dev \\
\hline Latitude $(\mathrm{N})$ & 61.2140 & 67.2364 & 67.8667 & 71.9015 & \\
\hline Longitude (E) & 50.5029 & 93.4761 & 92.2031 & 130.7293 & \\
\hline Altitude (m a.s.l) & 2 & 154 & 102 & 805 & 195 \\
\hline $\begin{array}{l}\text { Distance to } \\
\text { coast }(\mathrm{km})\end{array}$ & 16 & 408 & 259 & 5000 & 602 \\
\hline $\mathrm{pH}$ & 5.1 & 7.5 & 7.4 & 9.5 & 0.8 \\
\hline $\begin{array}{l}\text { Conductivity } \\
\qquad\left(\mu \mathrm{Scm}^{-1}\right)\end{array}$ & 2.4 & 73.7 & 40.0 & 356.0 & 83.9 \\
\hline Water depth (m) & 0.7 & 4.1 & 2.6 & 25.0 & 4.4 \\
\hline$T_{\text {july }}\left({ }^{\circ} \mathrm{C}\right)$ & 8.8 & 13.5 & 13.2 & 18.9 & 3.2 \\
\hline$T_{\text {jan }}\left({ }^{\circ} \mathrm{C}\right)$ & -39.4 & -27.8 & -29.4 & -15.5 & 8.8 \\
\hline Continentality Index & 31 & 56 & 55 & 91 & 18 \\
\hline $\begin{array}{l}\text { Mean annual } \\
\text { precipitation }(\mathrm{mm})\end{array}$ & 242 & 390 & 418 & 640 & 121 \\
\hline $\mathrm{Cl}^{-}\left(\mu e q \mathrm{l}^{-1}\right)$ & 2 & 43 & 27 & 288 & 49 \\
\hline $\mathrm{SO}_{4}^{2-}\left(\mu \mathrm{eq} \mathrm{l}^{-1}\right)$ & 1 & 50 & 28 & 760 & 97 \\
\hline $\mathrm{Ca}^{2+}\left(\mu \mathrm{eq} \mathrm{l}^{-1}\right)$ & 18 & 409 & 284 & 1587 & 379 \\
\hline $\operatorname{Mg}^{2+}\left(\mu \mathrm{eq} \mathrm{I}^{-1}\right)$ & 15 & 261 & 123 & 1727 & 359 \\
\hline $\mathrm{Na}^{+}\left(\mu \mathrm{eq} \mathrm{l}^{-1}\right)$ & 10 & 115 & 52 & 813 & 156 \\
\hline
\end{tabular}

Table 3

Summary of environmental data for the 157 Norwegian lakes.

\begin{tabular}{|c|c|c|c|c|c|}
\hline & \multicolumn{5}{|c|}{ Norwegian lakes (157 lakes) } \\
\hline & Minimum & Median & Mean & Maximum & Std dev \\
\hline Latitude $(\mathrm{N})$ & 58.08 & 61.54 & 64.71 & 79.8 & \\
\hline Longitude (E) & 5.005 & 8.862 & 11.27 & 31.038 & \\
\hline Altitude (m a.s.l) & 5 & 260 & 484 & 1594 & 473 \\
\hline $\begin{array}{l}\text { Distance to } \\
\text { coast }(\mathrm{km})\end{array}$ & 0 & 42 & 70 & 250 & 71 \\
\hline $\mathrm{pH}$ & 4.66 & 6.37 & 6.4 & 8.4 & 0.7 \\
\hline $\begin{array}{l}\text { Conductivity } \\
\qquad\left(\mu \mathrm{S} \mathrm{cm}^{-1}\right)\end{array}$ & 4 & 33 & 51.4 & 367 & 55.5 \\
\hline Water depth (m) & 0.5 & 7 & 8.1 & 29 & 5.9 \\
\hline$T_{\text {july }}\left({ }^{\circ} \mathrm{C}\right)$ & 3.5 & 10.5 & 10.3 & 16 & 3.5 \\
\hline$T_{\mathrm{jan}}\left({ }^{\circ} \mathrm{C}\right)$ & -15.6 & -7.6 & -7.5 & 2.6 & 4.8 \\
\hline Continentality index & -1 & 12 & 14 & 29 & 7 \\
\hline $\begin{array}{l}\text { Mean annual } \\
\text { precipitation }(\mathrm{mm})\end{array}$ & 390 & 796 & 995 & 2700 & 631 \\
\hline $\mathrm{Cl}^{-}\left(\mu \mathrm{eq} \mathrm{l}^{-1}\right)$ & 2 & 67 & 147 & 2342 & 254 \\
\hline $\mathrm{SO}_{4}^{2-}\left(\mu \mathrm{eq} \mathrm{l}^{-1}\right)$ & 7 & 46 & 72 & 1226 & 112 \\
\hline $\mathrm{Ca}^{2+}\left(\mu \mathrm{eq} \mathrm{l}^{-1}\right)$ & 20 & 99 & 233 & 3004 & 355 \\
\hline $\mathrm{Mg}^{2+}\left(\mu \mathrm{eql} \mathrm{l}^{-1}\right)$ & 7 & 44 & 95 & 930 & 140 \\
\hline $\mathrm{Na}^{+}\left(\mu \mathrm{eq} \mathrm{l} \mathrm{l}^{-1}\right)$ & 7 & 78 & 151 & 2127 & 224 \\
\hline
\end{tabular}

\section{Results}

\subsection{Species-environment relationships in the Russian lakes}

Concentrations of sodium, magnesium and chloride ions, and consequently the conductivity of the lakes, are related to climatic parameters such as summer temperature, precipitation and continentality (Table 1, Appendix A). High concentrations of these ions and the associated high conductivity measured in lakes from Central Yakutia suggest their hydrology is strongly affected by the extreme continentality and negative hydrological balance of the region (Kumke et al., 2007). The extremes in electrical conductivity, chloride and sodium ions result primarily from extreme values in two lakes (Y1740 and Y1741). As expected, July air temperature is strongly negatively correlated to latitude (Pearson productmoment correlation coefficient, $r=-0.96$ ). Longitude is negatively correlated to January air temperatures, continentality index and annual and summer precipitation $(r>-0.77)$. Annual precipitation shows strong positive correlation with summer precipitation $(r=0.98) \cdot \mathrm{Mg}^{2+}$ and $\mathrm{Na}^{+}$ion concentrations and conductivity are

Table 4

Summary of environmental data for the 149-lakes in the CI data-set.

\begin{tabular}{|c|c|c|c|c|c|}
\hline & \multicolumn{5}{|c|}{ CI data-set lakes (149 lakes) } \\
\hline & Minimum & Mean & Median & Maximum & Std dev \\
\hline Latitude (N) & 58.0767 & 64.7492 & 62.3833 & 71.9015 & 4.7694 \\
\hline Longitude (E) & 5.0767 & 39.1043 & 11.4467 & 128.8992 & 42.1657 \\
\hline Altitude ( $\mathrm{m}$ a.s.l) & 2 & 345 & 206 & 1194 & 341 \\
\hline $\begin{array}{l}\text { Distance to } \\
\text { coast (km) }\end{array}$ & 1 & 116 & 75 & 548 & 137 \\
\hline $\mathrm{pH}$ & 4.66 & 6.64 & 6.68 & 9.10 & 0.75 \\
\hline $\begin{array}{l}\text { Conductivity } \\
\qquad\left(\mu \mathrm{S} \mathrm{cm}^{-1}\right)\end{array}$ & 2.4 & 42.6 & 34.0 & 173.0 & 31.8 \\
\hline Water depth (m) & 0.5 & 7.3 & 6.2 & 26.0 & 5.6 \\
\hline$T_{\text {july }}\left({ }^{\circ} \mathrm{C}\right)$ & 8.8 & 11.8 & 11.7 & 15.3 & 1.9 \\
\hline$T_{\text {jan }}\left({ }^{\circ} \mathrm{C}\right)$ & -36.5 & -13.2 & -10.3 & 0.8 & 11.3 \\
\hline Continentality Index & 0 & 26 & 20 & 70 & 19 \\
\hline $\begin{array}{l}\text { Mean annual } \\
\text { precipitation }(\mathrm{mm})\end{array}$ & 269 & 921 & 570 & 2700 & 674 \\
\hline $\mathrm{Cl}^{-}\left(\mu \mathrm{eq} \mathrm{l}^{-1}\right)$ & 2 & 96 & 41 & 677 & 127 \\
\hline $\mathrm{SO}_{4}^{2-}\left(\mu \mathrm{eq} \mathrm{l}^{-1}\right)$ & 5 & 69 & 44 & 760 & 84 \\
\hline $\mathrm{Ca}^{2+}\left(\mu \mathrm{eq} \mathrm{I}^{-1}\right)$ & 26 & 243 & 144 & 1585 & 258 \\
\hline $\mathrm{Mg}^{2+}\left(\mu \mathrm{eq} \mathrm{I}^{-1}\right)$ & 11 & 93 & 62 & 609 & 97 \\
\hline $\mathrm{Na}^{+}\left(\mu \mathrm{eq} \mathrm{l}^{-1}\right)$ & 10 & 106 & 62 & 654 & 111 \\
\hline
\end{tabular}


also positively correlated $(r>0.78)$. These relationships suggest there is considerable redundancy within the environmental variables.

In total, 132 chironomid taxa were identified from the surface sediment samples of the 100 Russian lakes. Of these 42 taxa occurred in 3 or fewer lakes. The majority of these rare taxa occur at less than 5\% abundance in any lake, the exceptions are Propsilocerus lacustristype with a maximum abundance of $7.4 \%$, Parachaetocladius (6.2\%), Paralauterborniella (6.7\%) and Propsilocerus jacuticus-type (6.5\%). Whilst none of the taxa occurred in all the lakes, the most common are Psectrocladius sordidellus-type which occurred in $87 \%$ of the lakes, Procladius (77\%), Tanytarsus lugens-type (75\%), Cladotanytarsus mancus-type (71\%) and Chironomus anthracinus-type (66\%). Hydrobaenus conformis-type, Corynocera oliveri-type, Zalutschia type B and Abiskomyia are predominately associated with mean July air temperatures of less than $12^{\circ} \mathrm{C}$ (Fig. 2). Chironomus plumosustype, Paratanytarsus penicillatus-type, Glyptotendipes pallens-type and Cricotopus laricomalis-type are more abundant in, and Einfeldia restricted to, lakes with July air temperatures greater than $16^{\circ} \mathrm{C}$.

Detrended correspondence analysis (DCA) of the species data produces an axis 1 gradient length of 3.78 standard deviation units, with an eigenvalue of 0.468 , suggesting that unimodal-based numerical methods are most appropriate for further analysis (Birks, 1998). Canonical correspondence analysis (CCA) was undertaken on the 100-lake data-set with 18 environmental variables. Forward selection, using Monte Carlo permutation tests with 499 unrestricted permutations, indicates that six environmental variables (mean July air temperature, continentality, mean annual precipitation, tundra vegetation, water depth and $\mathrm{Ca}^{2+}$ concentrations) explain significant proportions $(p<0.05)$ of the explained variance (Fig. 3a, Table 5). The six selected variables were then used as single variables in a set of CCAs. The chironomid assemblages are most strongly correlated with mean July air temperature and continentality which give eigenvalue ratios of $1.169\left(\lambda_{1} / \lambda_{2}=0.374 /\right.$ $0.320)$ and $0.730\left(\lambda_{1} / \lambda_{2}=0.267 / 0.366\right)$, respectively. These high ratios indicate that these variables may be suitable for the development of inference models.

Fig. 3b presents correlation biplots of the CCA ordination based on 100 lakes, 132 taxa, and 6 significant environmental variables. The CCA results suggest Zalutschia zalutschicola-type and Limnophyes are closely associated with deep lakes and high mean annual precipitation (Fig. 3b). Zalutschia (Moller Pillot and Buskens, 1990) and some species of Limnophyes (Brodin, 1986) are associated with aquatic macrophytes. The majority of Russian lakes are on gently undulating tundra, so increasing precipitation may result in increased water depth and lake area, thereby increasing the size of the littoral zone and the area available for macrophyte growth. Limnophyes typically occurs in very shallow water (Kansanen, 1985; Hofmann, 1998), Massaferro and Brooks (2002) suggested that high abundances, in a sediment core from southern Chile, were associated with periods of low lake levels resulting from a decline in precipitation. The terrain in Chile is mountainous with steep-sided, tectonically controlled valleys. Therefore the impact of changing precipitation on water depth and the size of the littoral zone may depend on lake morphometry and the surrounding topography. From the CCA (Fig. 3b) it is difficult to distinguish if individual taxa are responding to mean July air temperatures and/or continentality as taxa such as Einfeldia, C. plumosus-type and C. laricomalis-type are most abundant in the Yakutian lakes with the warmest July air temperatures and most extreme continentality.

\subsection{Comparisons of the Russian and Norwegian assemblages}

The Norwegian training set comprises 157 lakes from Svalbard and mainland Norway. Fewer lakes were sampled in Russia (100 lakes) due to economic and logistic constraints. Potentially combining the data-sets could improve the representation of chironomid assemblages and individual taxa along the environmental gradients. But this would only be appropriate if the composition of the chironomid assemblages and responses of

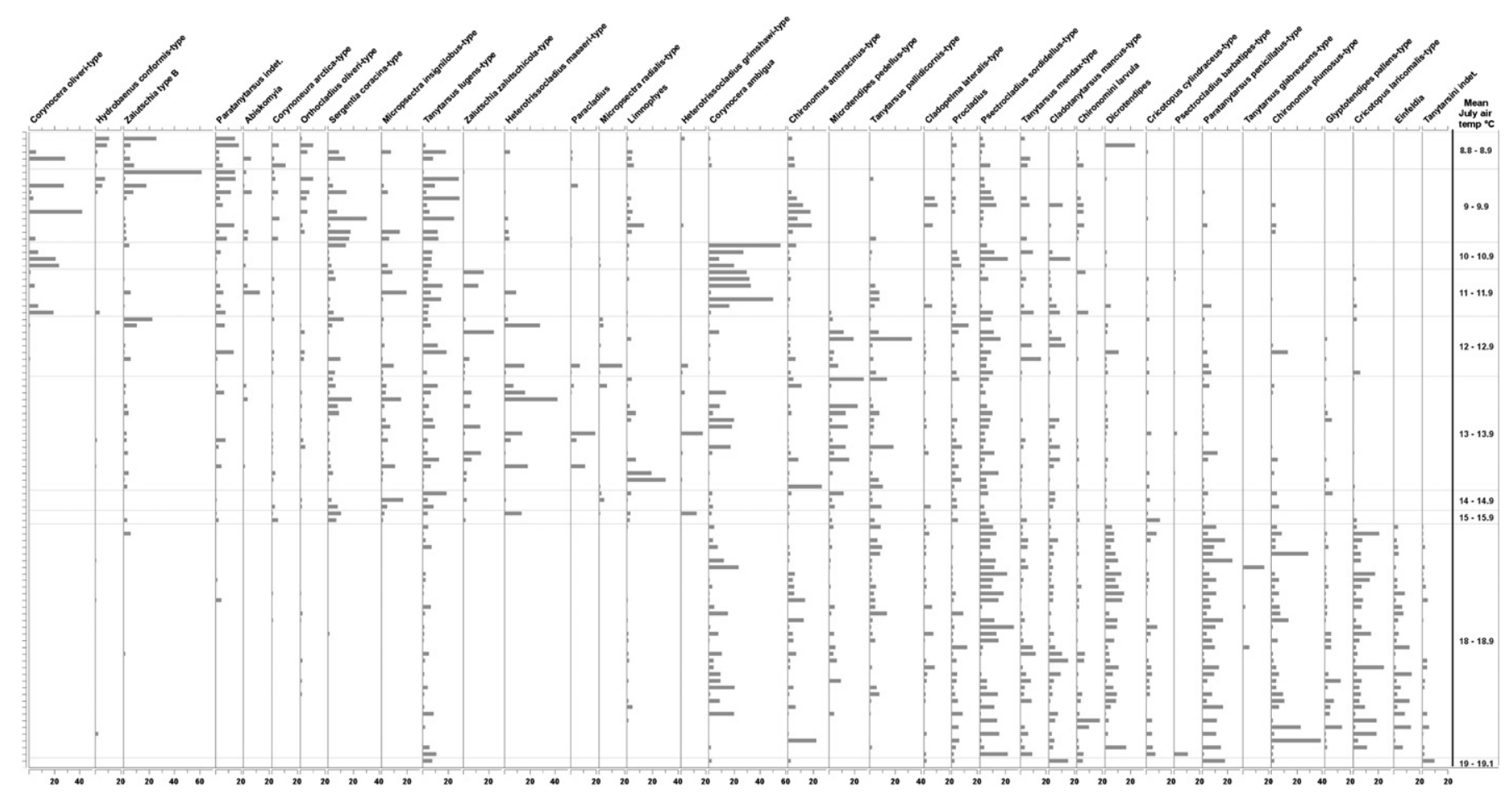

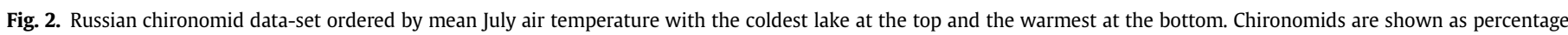
abundance, for all taxa with abundances greater than $10 \%$ (100 lakes). 
a

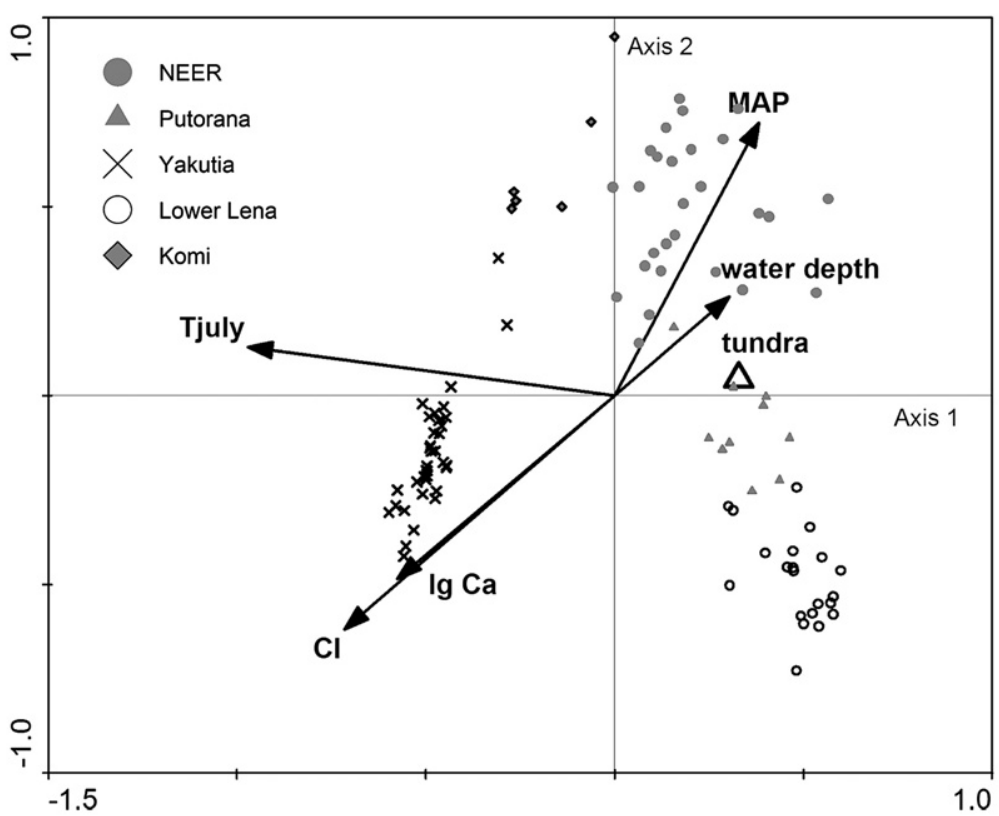

b

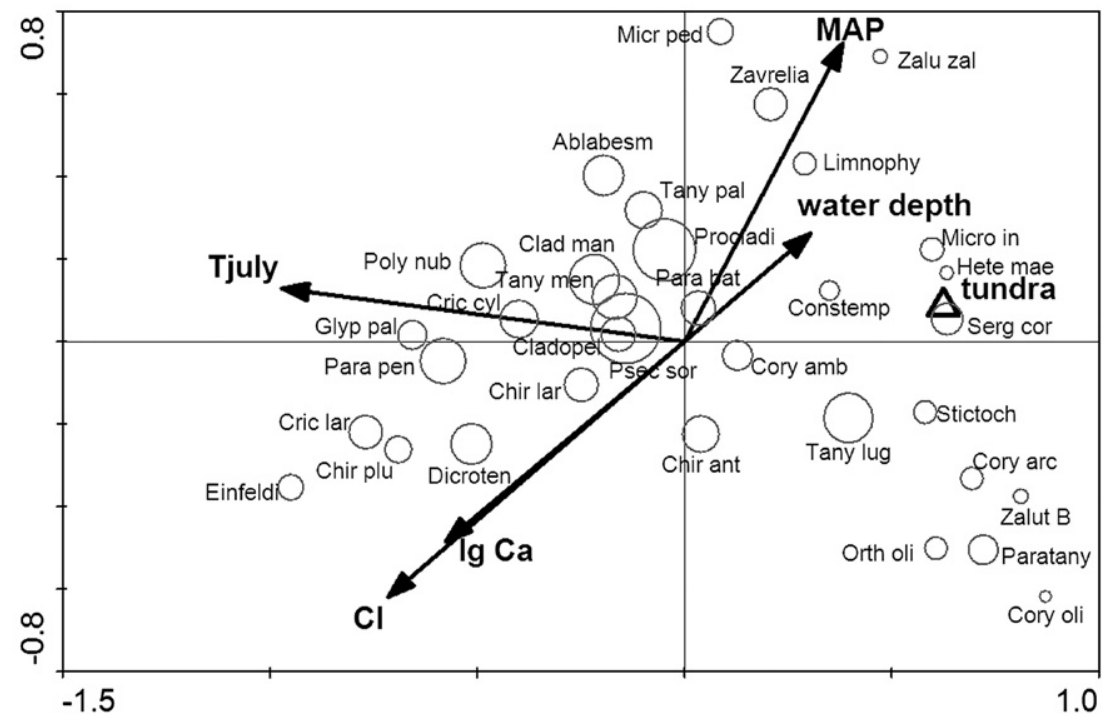

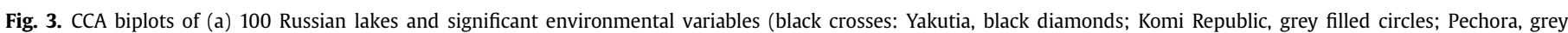

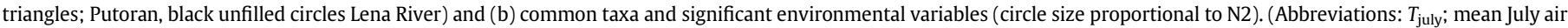
temperature, $\mathrm{CI}$; continentality index, MAP; mean annual precipitation, tundra; tundra vegetation and lg Ca; log of calcium ion concentrations).

Table 5

Significant environmental variables identified by forward selection in CCA of 100 Russian lakes and the variance they explain.

\begin{tabular}{llll}
\hline Variable & $\begin{array}{l}\text { Variance } \\
\text { explained }\end{array}$ & $\begin{array}{l}\text { \% total } \\
\text { variance } \\
\text { explained }\end{array}$ & $\begin{array}{l}\text { Significance } \\
\text { level }\end{array}$ \\
\hline Mean July air temperature $\left(T_{\text {july }}\right)$ & 0.37 & 43.0 & $p<0.002$ \\
Continentality $(\mathrm{CI})$ & 0.16 & 18.6 & $p<0.002$ \\
Mean annual precipitation (MAP) & 0.09 & 10.5 & $p<0.002$ \\
Tundra vegetation (tundra) & 0.08 & 9.3 & $p<0.004$ \\
Water depth & 0.08 & 9.3 & $p<0.006$ \\
Log Ca ${ }^{2+}$ conc (lg Ca) & 0.08 & 9.3 & $p<0.002$ \\
Total variance explained & 0.86 & & \\
Total variance & 3.99 & & \\
\hline
\end{tabular}

individual taxa are similar in the two geographic regions. The fauna from Birgervatnet, one of the Svalbard lakes, is composed of a single taxon Hydrobaenus lugubris-type so this lake was deleted from the Norwegian data-set reducing the gradient length of the first DCA axis from 6.6 to 4.4 SD units in the Norwegian set.

In compiling the Norwegian data-set, lakes were carefully selected to maximise the July temperature gradient and provide an even distribution of lakes over that gradient whilst minimising variation in the other parameters (Brooks and Birks, 2000). The standard deviations of variables such as $\mathrm{pH}$, conductivity, and major cations are, therefore, lower in the Norwegian data-set compared to the Russian data (Table 3 ) as primarily naturally acid or circum-neutral, clearwater lakes were selected. However the maxima and standard deviation of altitude and annual precipitation are greater in the Norwegian data-set. These variables are spatially correlated as the main mountain range in Norway runs along the coast which results in high altitude lakes receiving greater orographic precipitation. 
In total, 142 chironomid taxa or morphotypes were identified in surface sediments from the 156 Norwegian lakes. Some taxa identified in the Russian surface sediments, such as Constempellina brevicosta and Einfeldia, are not found in the sampled Norwegian lakes and other taxa including Diamesa aberrata-type are found in the Norwegian lakes only. Taxa recorded in both Norway and Russia, or the two data-sets individually, are listed in Appendix B. Several taxa found only in the Norwegian lakes are associated with springs, streams or running water; for example Krenosmittia (Schmid, 1993), Rheotanytarsus (Pinder and Reiss, 1983), Rheocricotopus spp. (Cranston et al., 1983) and Parochlus (Brundin, 1983). Their occurrence may reflect the greater importance of surface inflow into the Norwegian lakes due to the high precipitation and mountainous terrain compared to the Russian lakes. Many of the common morphotypes, such as P. sordidellus-type T. lugens-type, Procladius and $C$. anthracinus-type, appear to be widespread throughout Norway and Russia. The taxa may either have a cosmopolitan distribution due to wide environmental tolerances or the species composition, and therefore possibly the temperature optima of the morphotypes may vary between geographical regions, indicating the existence of distinct regional morphotypes.

Canonical correspondence analysis (CCA), with forward selection, suggest there is a relationship between chironomid distribution and abundance in the Norwegian lakes and July air temperature (not shown) with distance to the coast, chloride ion concentrations, and continentality also being important environmental variables. Chironomid distribution and abundance, in the combined Norwegian-Russian data-set, show strongest relationships with mean July air temperature and continentality (Fig. 4, Table 6) giving eigenvalue ratios in constrained CCA of $0.783\left(\lambda_{1} / \lambda_{2}=0.311 / 0.397\right)$ for mean July air temperature and $0.479\left(\lambda_{1} / \lambda_{2}=0.231 / 0.482\right)$ for continentality. July air temperature and continentality explain similar percentages of the variance in the chironomid data in both the Russian and combined data-sets, approximately $40-43 \%$ attributed to July air temperature and $19-24 \%$ to continentality.

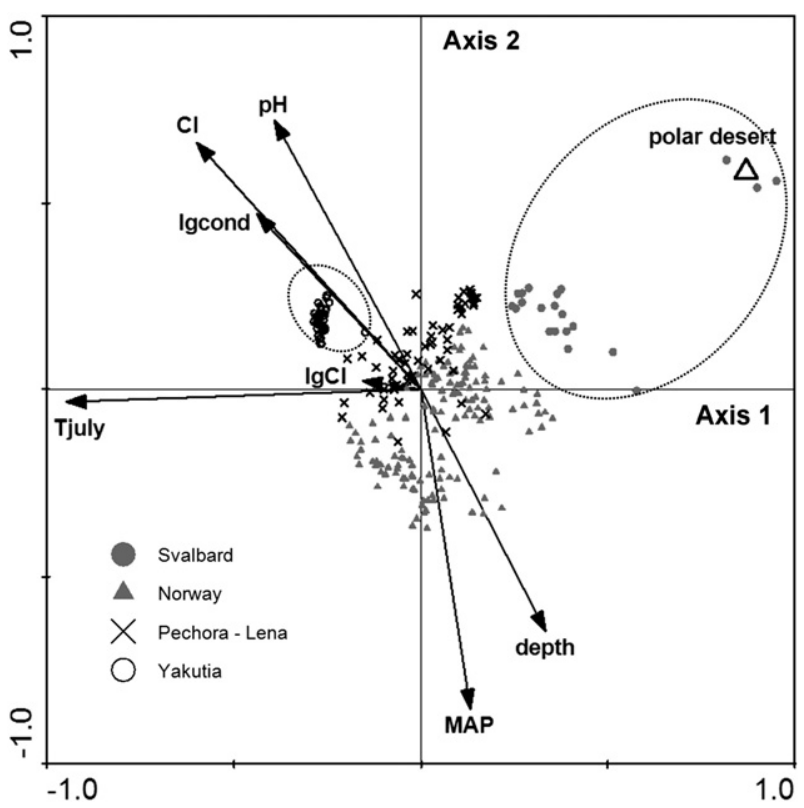

Fig. 4. CCA of the combined Norwegian and Russian lakes (157 from Norway and 100 from Russia) showing the significant environmental variables. Ovals highlight the compositionally distinct faunas from Svalbard (grey filled circles) and Yakutia (black unfilled circles). (Abbreviations: $T_{\text {july }}$; mean July air temperature, $\mathrm{CI}$; continentality index, lgcond: log of conductivity, $\operatorname{lgCl}$; log of chloride ion concentration, polar desert; polar desert vegetation, MAP; mean annual precipitation and depth; water depth).
Table 6

Significant environmental variables identified by forward selection in CCA of the combined Norwegian and Russian lakes and the variance they explain.

\begin{tabular}{|c|c|c|c|}
\hline$<$ Variable & $\begin{array}{l}\text { Variance } \\
\text { explained }\end{array}$ & $\begin{array}{l}\text { \% total } \\
\text { variance } \\
\text { explained }\end{array}$ & $\begin{array}{l}\text { Significance } \\
\text { level }\end{array}$ \\
\hline Mean July air temperature $\left(T_{\text {july }}\right)$ & 0.31 & 39.7 & $p<0.002$ \\
\hline Continentality $(\mathrm{CI})$ & 0.18 & 23.1 & $p<0.002$ \\
\hline Log conductivity (lgcond) & 0.08 & 10.3 & $p<0.002$ \\
\hline Water depth (depth) & 0.06 & 7.7 & $p<0.002$ \\
\hline Polar desert vegetation (polar desert) & 0.06 & 7.7 & $p<0.002$ \\
\hline Mean annual precipitation (MAP) & 0.04 & 5.1 & $p<0.002$ \\
\hline $\log \mathrm{Cl}^{-} \operatorname{conc}(\lg \mathrm{Cl})$ & 0.02 & 2.6 & $p<0.036$ \\
\hline $\mathrm{pH}$ & 0.03 & 3.8 & $p<0.012$ \\
\hline Total variance explained & 0.78 & & \\
\hline Total variance & 3.78 & & \\
\hline
\end{tabular}

\subsection{Comparisons of species composition in Russian and Norwegian data-sets}

Using squared chord distance as a measure of dissimilarity in an analogue analysis, Norwegian lakes were selected as the closest analogue for $14 \%$ of the Russian lakes. By comparison only $5 \%$ of Norwegian lakes selected a Russian lake as the closest analogue, probably reflecting the greater number and geographically close proximity of sampled Norwegian lakes compared to Russian lakes. TWINSPAN of the chironomid assemblages from Norway and Russia, excluding Birgervatnet, suggests the Svalbard (Groups 1 and 2) and Yakutian lakes (Group 3) have distinctive faunas (Fig. 5). The first level of the TWINSPAN division separates assemblages with greater than $2 \%$ Orthocladius type S and an absence of Tanytarsus mendaxtype from the remaining lakes. Lakes with significant abundances of Orthocladius type $S$ are on Svalbard and three lakes in northern Norway (B98-3, 99-23 and 99-25). The second division separates these three Norwegian lakes and lake $\mathrm{N}$ from Svalbard from the remaining Svalbard lakes, with the majority of Svalbard lakes are dominated by Diamesa zernyi/cinerella-type and Pseudodiamesa. The Svalbard lakes experience the coldest July air temperatures $\left(3.5-6.5^{\circ} \mathrm{C}\right)$ of the Norwegian data-set and these taxa are cold stenotherms (Brooks et al., 2007). In the fifth division the presence of Einfeldia and C. laricomalis-type at greater than $2 \%$ abundance and the absence of Sergentia coracina-type separates the Yakutian lakes and lake K-7 (36 lakes) from a larger group of 76 of Russian and Norwegian lakes. S. coracina-type is a cold stenotherm (Brundin, 1956; Brodin, 1986) and Einfeldia is usually indicative of eutrophic water (Sæther, 1979; Brooks et al., 2001). Eutrophic conditions are more common in warm lakes but Einfeldia is also found in relatively cool conditions in Switzerland (Heiri, 2001). With the exception of the assemblages from the Yakutian lakes and lake $\mathrm{K}-7$, the remaining Russian assemblages are compositionally similar to the Norwegian assemblages at the fourth TWINSPAN level.

\subsection{Species-July air temperature relationships}

Taxon responses to July air temperature were examined in the Norwegian data-set (excluding Birgervatnet) and 100-lake Russian data-set by fitting response models to species abundance and presence/absence data for taxa with 10 or more occurrences using HOF and GLR models. Species mean July air temperature optima were also estimated by weighted averaging. The HOF models suggest $85 \%$ of the taxa in the Russian data-set with 10 or more occurrences have a statistically significant response to mean July air temperature, however only $47 \%$ have a unimodal response compared with $76 \%$ in the Norwegian data-set. A number of taxa were assigned zero values or values which clearly lay outside the environmental range of the study areas, for example $-99.8^{\circ} \mathrm{C}$ or 
Table 7

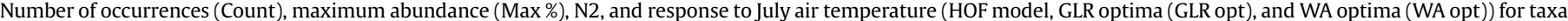

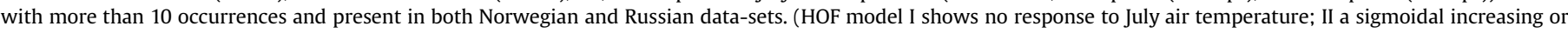
decreasing response, III a response which reaches a plateau; IV a unimodal response and $\mathrm{V}$ a skewed unimodal response).

\begin{tabular}{|c|c|c|c|c|c|c|c|c|c|c|c|c|}
\hline & \multicolumn{6}{|c|}{ Norway (156 lakes) } & \multicolumn{6}{|c|}{ Russia (100 lakes) } \\
\hline & Count & $\operatorname{Max} \%$ & N2 & HOF & GLR opt ${ }^{\circ} \mathrm{C}$ & WA opt ${ }^{\circ} \mathrm{C}$ & Count & $\operatorname{Max} \%$ & N2 & HOF & GLR opt ${ }^{\circ} \mathrm{C}$ & WA opt ${ }^{\circ} \mathrm{C}$ \\
\hline \multicolumn{13}{|l|}{ Tanypodinae } \\
\hline Ablabesmyia & 98 & 15.2 & 64.3 & IV & 13.1 & 12.4 & 46 & 8.2 & 32.5 & $\mathrm{~V}$ & 15.8 & 15.7 \\
\hline Procladius & 118 & 12.7 & 82.8 & IV & 12.6 & 11.4 & 77 & 13.6 & 50.3 & IV & 15.1 & 14.8 \\
\hline \multicolumn{13}{|l|}{ Chironomini } \\
\hline Chironomus anthracinus-type & 60 & 20.1 & 23.0 & II & 0 & 12.6 & 66 & 26.7 & 29.2 & II & 0 & 14.1 \\
\hline Chironomini 1 st instar larvula & 41 & 9.8 & 19.4 & II & 0 & 13.6 & 57 & 18.6 & 26.4 & I & 0 & 15.4 \\
\hline Chironomus plumosus-type & 12 & 11.3 & 3.6 & IV & 13.7 & 13.6 & 49 & 39.4 & 21.2 & II & 0 & 17.3 \\
\hline Cladopelma & 49 & 7.4 & 27.6 & II & 20.3 & 12.5 & 50 & 11.2 & 27.3 & II & 0 & 15.2 \\
\hline Dicrotendipes & 72 & 20.7 & 28.5 & IV & 13.2 & 12.2 & 60 & 23.6 & 33.0 & II & 0 & 16.6 \\
\hline Microtendipes pedellus-type & 74 & 46.2 & 20.5 & IV & 12.5 & 12.0 & 43 & 27.2 & 20.3 & IV & 14.6 & 14.3 \\
\hline Parachironomus varus-type & 15 & 4.9 & 7.2 & II & 0 & 14.2 & 28 & 6.6 & 18.3 & II & 0 & 17.0 \\
\hline Phaenopsectra flavipes-type & 16 & 4.7 & 9.6 & IV & 14.0 & 14.0 & 15 & 2.8 & 12.2 & IV & 14.6 & 14.0 \\
\hline Polypedilum nubeculosum-type & 51 & 12.6 & 21.5 & IV & 15.4 & 13.3 & 52 & 8.3 & 36.5 & IV & 16.3 & 16.8 \\
\hline Sergentia coracina-type & 119 & 55.0 & 53.8 & IV & 12.8 & 11.5 & 50 & 30.8 & 25.2 & II & 10.1 & 12.0 \\
\hline Stictochironomus & 21 & 3.8 & 15.0 & IV & 11.5 & 11.3 & 29 & 8.3 & 17.7 & II & 11.4 & 12.3 \\
\hline Pseudochironomus & 20 & 5.6 & 11.4 & IV & 15.9 & 14.5 & 18 & 9.5 & 12.7 & II & 18.2 & 18.3 \\
\hline \multicolumn{13}{|l|}{ Tanytarsini } \\
\hline Cladotanytarsus mancus-type & 42 & 23.4 & 13.5 & IV & 12.5 & 11.6 & 71 & 16.7 & 40.1 & II & 16.9 & 15.4 \\
\hline Corynocera ambigua & 38 & 52.4 & 18.0 & IV & 9.9 & 10.1 & 60 & 56.5 & 23.9 & IV & 12.4 & 13.8 \\
\hline Corynocera oliveri-type & 11 & 47.6 & 2.3 & IV & 8.0 & 8.7 & 20 & 41.8 & 8.5 & IV & 10.2 & 10.2 \\
\hline Micropsectra insignilobus-type & 79 & 30.5 & 32.1 & IV & 9.5 & 9.7 & 39 & 20.1 & 18.2 & IV & 12.2 & 12.3 \\
\hline Micropsectra radialis-type & 54 & 96.3 & 20.7 & II & -2.4 & 5.2 & 14 & 18.2 & 4.8 & IV & 13.0 & 12.8 \\
\hline Paratanytarsus penicillatus-type & 72 & 26.0 & 30.2 & IV & 11.7 & 11.3 & 64 & 24.1 & 36.7 & II & 29.2 & 17.1 \\
\hline Paratanytarsus undiff. & 89 & 38.1 & 36.7 & IV & 8.6 & 9.3 & 41 & 18.6 & 23.2 & II & 0 & 11.1 \\
\hline Stempellinella - Zavrelia & 28 & 4.1 & 18.8 & IV & 12.6 & 11.9 & 41 & 9.4 & 26.2 & IV & 14.4 & 14.2 \\
\hline Tanytarsus lugens-type & 88 & 37.6 & 39.0 & IV & 8.9 & 9.6 & 75 & 28.8 & 39.6 & V & -48.3 & 12.7 \\
\hline Tanytarsus mendax-type & 94 & 18.8 & 55.6 & IV & 12.0 & 11.5 & 63 & 22.5 & 35.8 & II & 47.5 & 15.4 \\
\hline Tanytarsus pallidicornis-type & 64 & 15.8 & 31.9 & IV & 13.2 & 12.1 & 58 & 33.3 & 29.5 & IV & 14.8 & 14.8 \\
\hline \multicolumn{13}{|l|}{ Orthocladiinae } \\
\hline Corynoneura arctica-type & 62 & 6.7 & 35.8 & IV & 13.5 & 11.9 & 31 & 11.3 & 17.4 & II & -99.8 & 11.3 \\
\hline Cricotopus cylindraceus-type & 51 & 19.0 & 18.3 & IV & 13.3 & 12.8 & 49 & 11.3 & 30.1 & II & 17.4 & 16.6 \\
\hline Cricotopus laricomalis-type & 30 & 7.5 & 17.4 & V & 9.4 & 10.0 & 54 & 24.4 & 26.4 & II & 0 & 17.8 \\
\hline Cricotopus type P & 29 & 2.5 & 22.2 & IV & 11.1 & 11.0 & 24 & 6.2 & 15.2 & IV & 12.7 & 12.6 \\
\hline Heterotrissocladius grimshawi-type & 58 & 17.4 & 21.8 & IV & 11.5 & 11.2 & 13 & 17.9 & 5.8 & IV & 14.0 & 13.6 \\
\hline Heterotrissocladius maeaeri-type & 48 & 69.3 & 15.2 & IV & 9.1 & 9.6 & 25 & 42.2 & 9.8 & IV & 12.8 & 12.7 \\
\hline Hydrobaenus conformis-type & 19 & 46.1 & 4.0 & II & 0 & 5.4 & 17 & 11.2 & 8.4 & II & 0 & 10.4 \\
\hline Limnophyes - Paralimnophyes & 85 & 18.8 & 42.1 & IV & 0 & 12.6 & 55 & 30.4 & 17.6 & II & 12.6 & 13.2 \\
\hline Orthocladius oliveri-type & 34 & 22.9 & 8.6 & I & 0 & 10.2 & 29 & 11.0 & 17.1 & II & 0 & 11.5 \\
\hline Parakiefferiella bathophila-type & 54 & 9.3 & 28.3 & IV & 12.3 & 11.9 & 40 & 7.4 & 27.3 & I & 0 & 14.5 \\
\hline Parakiefferiella triquetra-type & 12 & 1.4 & 10.4 & IV & 12.3 & 11.8 & 16 & 7.4 & 10.4 & II & 10.1 & 11.2 \\
\hline Paraphaenocladius & 22 & 8.0 & 8.1 & IV & 11.5 & 11.3 & 12 & 4.9 & 8.3 & IV & 17.4 & 15.6 \\
\hline Psectrocladius barbatipes-type & 46 & 11.3 & 23.3 & IV & 12.7 & 12.3 & 14 & 13.0 & 4.1 & IV & 0 & 15.5 \\
\hline Psectrocladius septentrionalis-type & 77 & 24.8 & 33.2 & IV & 11.6 & 11.4 & 21 & 5.7 & 11.0 & IV & 14.0 & 13.5 \\
\hline Psectrocladius sordidellus-type & 133 & 30.8 & 91.9 & IV & 13.7 & 11.4 & 87 & 27.0 & 57.2 & I & 0 & 15.1 \\
\hline Pseudosmittia & 24 & 7.3 & 13.1 & II & 22.1 & 12.7 & 13 & 3.8 & 9.9 & IV & 14.6 & 14.5 \\
\hline Zalutschia type B & 42 & 24.6 & 13.7 & IV & 12.3 & 11.6 & 47 & 61.3 & 10.9 & II & 0 & 10.8 \\
\hline Zalutschia zalutschicola & 23 & 41.8 & 11.4 & V & 11.4 & 11.2 & 24 & 24.3 & 10.5 & IV & 12.7 & 12.7 \\
\hline
\end{tabular}

\subsection{Species-continentality relationships}

HOF models of the taxon-continentality relationship suggest $77 \%$ of the Russian taxa have a statistically significant response to the continentality index (CI). Fewer taxa (66\%) have a significant response in the Norwegian lakes which may reflect the short $\mathrm{CI}$ gradient in Norway. Continentality is calculated from, and therefore is not independent of, $T_{\text {july }}$. Therefore to minimise the risk of attributing a response to $T_{\text {july }}$ instead of continentality, the Norwegian and Russian data-sets were combined and a subset of 149 lakes selected. This excluded samples from the extremities of the $T_{\text {july }}$ gradient as all the coldest lakes (in Svalbard) have low CIs and all the warmest lakes (in Yakutia) have high CIs and, for these lakes, it is difficult to separate out the effects of temperature and continentality on chironomid distribution and abundance. Additional samples were excluded to even out the distribution of samples along the continentality gradient. For each $0.5{ }^{\circ} \mathrm{C}$ interval along the
July air temperature gradient, samples were selected so that the number of Norwegian lakes approximately equalled the number of Russian lakes for each interval, the total number of lakes in each $0.5^{\circ} \mathrm{C}$ interval did not exceed 10 and the widest range of $\mathrm{CI}$ was retained in each temperature interval.

Taxon responses to $\mathrm{CI}$ were examined in the 149 lake data-set by fitting response models to species abundance and presence/ absence data for taxa with 10 or more occurrences using HOF and GAM models. The fitted HOF models suggested 12 of the 82 taxa tested (14.6\%) have no statistically significant relationship to continentality (Table 7). However, the GAM models for an additional 25 taxa show fluctuations in abundance, rather than a definite trend, along the $\mathrm{CI}$ gradient which mean that additional data are required to determine whether the inferred-HOF relationships are reliable. The results vary as the taxon responses are more complex than the five specified HOF models; GAMs are data-driven and therefore not limited to an a priori model as in HOF. 


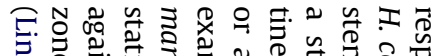

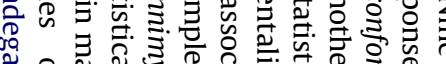

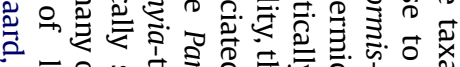

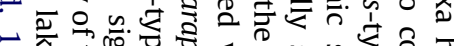

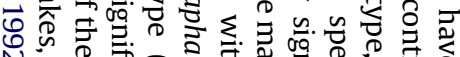
음 2 (0)

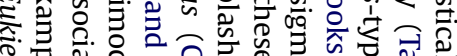

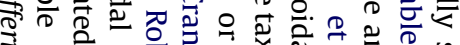

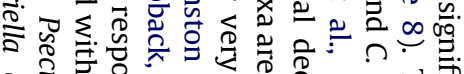

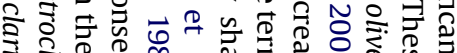

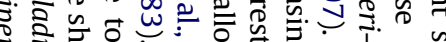
उ .

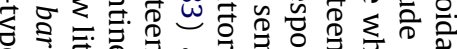
证

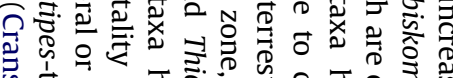

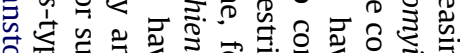

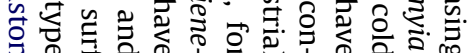
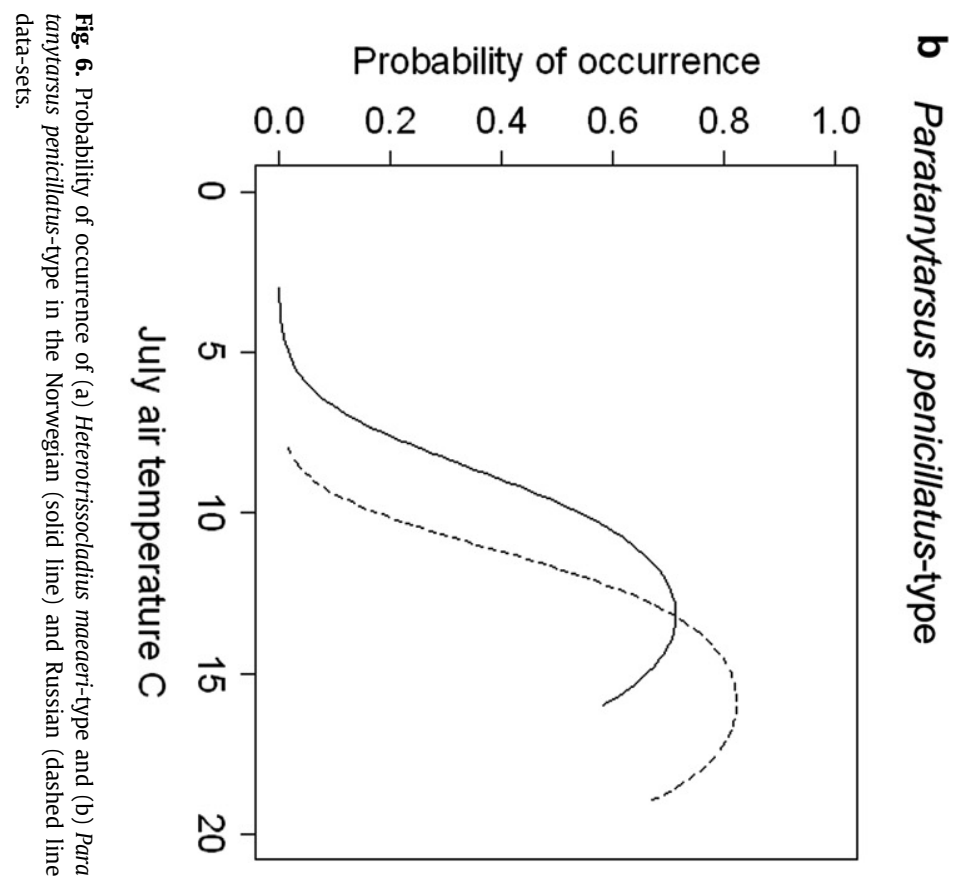

Probability of occurrence

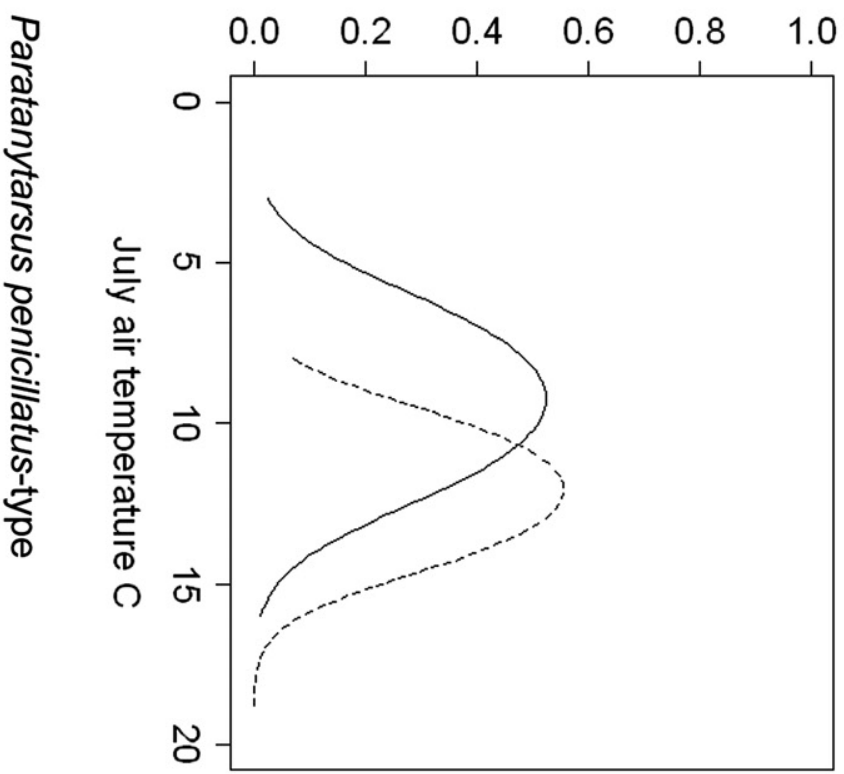

Table 8

HOF model responses to continentality in the combined Norwegian and Russian data-set (149 lakes, 82 taxa).

\begin{tabular}{|c|c|c|c|c|}
\hline HOF model I null response & $\begin{array}{l}\text { Show HOF response: but } \\
\text { insufficient data for GAM model }\end{array}$ & $\begin{array}{l}\text { HOF model II sigmoidal } \\
\text { decreasing response }\end{array}$ & $\begin{array}{l}\text { HOF model II sigmoidal } \\
\text { increasing response }\end{array}$ & $\begin{array}{l}\text { HOF models IV and V } \\
\text { unimodal response }\end{array}$ \\
\hline $\begin{array}{l}\text { Cricotopus cylindraceus-type } \\
\text { Cricotopus sylvestris-type } \\
\text { Cryptochironomus } \\
\text { Dicrotendipes } \\
\text { Heterotrissocladius maeaeri-type } \\
\text { Heterotrissocladius grimshawi-type } \\
\text { Limnophyes - Paralimnophyes } \\
\text { Orthocladius type S } \\
\text { Pagastiella } \\
\text { Paratanytarsus austriacus-type } \\
\text { Parakiefferiella bathophila-type } \\
\text { Phaenopsectra flavipes-type } \\
\text { Zalutschia zalutschicola }\end{array}$ & $\begin{array}{l}\text { Cladopelma lateralis-type } \\
\text { Corynocera ambigua } \\
\text { Corynoneura arctica-type } \\
\text { Corynoneura edwardsi-type } \\
\text { Corynoneura lobata-type } \\
\text { Cricotopus type C } \\
\text { Cricotopus type P } \\
\text { Glyptotendipes pallens-type } \\
\text { Macropelopia } \\
\text { Mesocricotopus } \\
\text { Microtendipes pedellus-type } \\
\text { Micropsectra insignilobus-type } \\
\text { Micropsectra radialis-type } \\
\text { Monodiamesa } \\
\text { Parakiefferiella nigra-type } \\
\text { Paratanytarsus penicillatus-type } \\
\text { Parachironomus varus-type } \\
\text { Paracladius } \\
\text { Paramerina } \\
\text { Paratanytarsus undiff. } \\
\text { Polypedilum nubeculosum-type } \\
\text { Stictochironomus rosenschoeldi-type } \\
\text { Tanytarsus 'no spur' } \\
\text { Zavrelia - Stempellinella }\end{array}$ & $\begin{array}{l}\text { Ablabesmyia } \\
\text { Heterotanytarsus apicalis-type } \\
\text { Orthocladius undiff. } \\
\text { Paracladopelma } \\
\text { Paraphaenocladius } \\
\text { Protanypus } \\
\text { Psectrocladius septentrionalis-type } \\
\text { Psectrocladius sordidellus-type } \\
\text { Pseudorthocladius } \\
\text { Pseudosmittia } \\
\text { Sergentia coracina-type } \\
\text { Smittia - Parasmittia } \\
\text { Synorthocladius } \\
\text { Tanytarsus chinyensis-type } \\
\text { Thienemanniella clavicornis-type } \\
\text { Thienemannimyia-group }\end{array}$ & $\begin{array}{l}\text { Abiskomyia } \\
\text { Chironomus anthracinus-type } \\
\text { Chironomini 1st instar larvula } \\
\text { Chironomus plumosus-type } \\
\text { Cricotopus intersectus-type } \\
\text { Hydrobaenus conformis-type } \\
\text { Orthocladius oliveri-type } \\
\text { Tanytarsus lugens-type } \\
\text { Zalutschia type B } \\
\\
\text { HOF model III plateau response } \\
\text { Constempellina - Thienemanniola } \\
\text { Corynocera oliveri-type } \\
\text { Cricotopus laricomalis-type } \\
\text { Procladius } \\
\text { Tanytarsus mendax-type }\end{array}$ & $\begin{array}{l}\text { Cladotanytarsus mancus-type } \\
\text { Corynoneura type A } \\
\text { Endochironomus albipennis-type } \\
\text { Endochironomus impar-type } \\
\text { Eukiefferiella claripennis-type } \\
\text { Heterotrissocladius marcidus-type } \\
\text { Lauterborniella } \\
\text { Micropsectra pallidula-type } \\
\text { Parakiefferiella triquetra-type } \\
\text { Parakiefferiella type A } \\
\text { Phaenopsectra type A } \\
\text { Psectrocladius barbatipes-type } \\
\text { Pseudochironomus } \\
\text { Tanytarsus pallidicornis-type } \\
\text { Zavrelimyia }\end{array}$ \\
\hline
\end{tabular}


et al., 1983; Lindegaard, 1992). Some thermophilic taxa such as Heterotrissocladius marcidus-type and Micropsectra pallidula-type (Brooks et al., 2007) have low CI optima of 12 and 13, respectively, whereas cold stenotherms such as $P$. triquetra-type have high $\mathrm{CI}$ optima, $\mathrm{CI}=40$ (Table 9). Many of the genera which show no statistically significant response to continentality have wide geographical distributions. Limnophyes (Cranston et al., 1983) and Dicrotendipes (Pinder and Reiss, 1983), for example, have worldwide distributions. Therefore each genus may be represented by different species along the continentality gradient.

\subsection{Development of inference models}

\subsubsection{Chironomid-inferred July air temperature model}

Chironomid assemblages show a strong relationship with mean July air temperature in both the Russian and Norwegian data-sets. The higher July temperature optima for the Russian taxa suggest that it is inappropriate to combine the two data-sets. A chironomidbased mean July air temperature transfer function was developed based on the 100 Russian lakes and 132 taxa. Performance statistics indicated the weighted average partial least squares (WA-PLS) 2-component model (Table 10a) performed best with a high coefficient of determination $\left(r_{\text {jack }}^{2}=0.90\right)$ and low $\operatorname{RMSEP}\left(1.09^{\circ} \mathrm{C}\right)$. The lakes in the Russian data-set are unevenly distributed along the July air temperature gradient as 36 of 100 lakes were located in Central Yakutia with air temperatures of $18-19{ }^{\circ} \mathrm{C}$. Many of these lakes have extremely high conductivity due to the low precipitation and/ or have high nutrient levels (Table 1, Appendix A) and all are faunistically distinct from the majority of the remaining Russian lakes (Fig. 3). Therefore 19 lakes from Yakutia were excluded from the training set and a second chironomid-inferred July air temperature (C-IT) transfer function was constructed, based on 81 lakes. Only the 89 taxa with 3 or more occurrences were included in this inference model. To generate robust inference models the apparent and cross-validated predictive powers (RMSE/RMSEP ratio) must be similar. To achieve this the number of taxa should approximately equal the number of lakes (Racca et al., 2003). Performance statistics indicated the weighted average partial least squares (WA-PLS) 2-component model (Table 10b) performed better than the 100-lake model with a higher coefficient of determination $\left(r_{\mathrm{jack}}^{2}=0.92\right)$ and lower RMSEP $\left(0.89^{\circ} \mathrm{C}\right)$. The model overpredicts temperatures below $13{ }^{\circ} \mathrm{C}$ and under-predicts above $13{ }^{\circ} \mathrm{C}$ and has a maximum bias of $\pm 1.28^{\circ} \mathrm{C}$ (Fig. 7a). These performance statistics compare favourably with other chironomid-based temperature-inference models (Brooks, 2006a).

Table 9

GLR and WA derived continentality indices optima for taxa showing a unimodal response to continentality. Abbreviations follow Table 7 .

\begin{tabular}{lllllll}
\hline Unimodal response & Count & Max \% & N2 & HOF & $\begin{array}{l}\text { GLR } \\
\text { opt.CI }\end{array}$ & $\begin{array}{l}\text { WA } \\
\text { opt CI }\end{array}$ \\
\hline Cladotanytarsus mancus-type & 65 & 4.8 & 48.7 & IV & 39 & 33 \\
Corynoneura type A & 24 & 2.9 & 20.1 & IV & 20 & 16 \\
Endochironomus albipennis-type & 17 & 1.7 & 15.4 & V & 42 & 38 \\
Endochironomus impar-type & 14 & 1.9 & 12.0 & IV & 36 & 34 \\
Eukiefferiella claripennis-type & 40 & 4.4 & 30.4 & IV & 0 & 16 \\
Heterotrissocladius marcidus-type & 63 & 5.0 & 50.2 & IV & 9 & 12 \\
Lauterborniella & 20 & 2.9 & 16.7 & IV & 18 & 16 \\
Micropsectra pallidula-type & 20 & 2.1 & 17.6 & IV & 15 & 13 \\
Parakiefferiella triquetra-type & 27 & 2.7 & 22.8 & IV & 54 & 40 \\
Parakiefferiella type A & 27 & 2.8 & 21.9 & IV & 21 & 17 \\
Phaenopsectra type A & 24 & 1.8 & 21.1 & IV & 18 & 15 \\
Psectrocladius barbatipes-type & 52 & 3.4 & 44.3 & IV & 21 & 21 \\
Pseudochironomus & 16 & 2.4 & 13.5 & IV & 16 & 15 \\
Tanytarsus pallidicornis-type & 82 & 5.8 & 65.0 & IV & 35 & 28 \\
Zavrelimyia & 26 & 2.6 & 22.2 & IV & 10 & 11 \\
\hline
\end{tabular}

Table 10

Performance statistics for the chironomid-inferred mean July air temperature transfer functions for (a) the 100 Russian lake data-set, (b) the 81 Russian lake dataset and (c) the 157-lake Norwegian lake data-set. The model with the statistically best performance is shown in bold. Max $=$ maximum, inv $=$ inverse, cla $=$ classical, $\mathrm{TOL}=$ tolerance.

\begin{tabular}{|c|c|c|c|c|c|}
\hline Model & $r_{\text {jack }}^{2}$ & $\mathrm{RMSEP}_{\text {jack }}$ & Mean bias jack & Max bias jack & $\begin{array}{l}\text { Reduction } \\
\text { in prediction } \\
\text { error }(\%)\end{array}$ \\
\hline \multicolumn{6}{|l|}{$a$} \\
\hline \multicolumn{6}{|l|}{ Inverse } \\
\hline WA (inv) & 0.85 & -0.01 & 2.17 & 1.36 & - \\
\hline WA - TOL (inv) & 0.81 & -0.25 & 2.47 & 1.53 & - \\
\hline \multicolumn{6}{|l|}{ Classical } \\
\hline WA (cla) & 0.85 & -0.01 & 2.36 & 1.39 & - \\
\hline WA - TOL (cla) & 0.81 & -0.27 & 2.62 & 1.59 & - \\
\hline WA-PLS (1) & 0.85 & -0.04 & 2.15 & 1.36 & - \\
\hline WA-PLS (2) & 0.90 & 0.00 & 1.19 & 1.09 & 19.43 \\
\hline WA-PLS (3) & 0.90 & -0.01 & 1.07 & 1.12 & -1.91 \\
\hline WA-PLS (4) & 0.88 & -0.01 & 0.90 & 1.19 & -6.71 \\
\hline WA-PLS (5) & 0.86 & -0.03 & 1.08 & 1.29 & -8.00 \\
\hline \multicolumn{6}{|l|}{$b$} \\
\hline \multicolumn{6}{|l|}{ Inverse } \\
\hline WA (inv) & 0.86 & 1.19 & -0.02 & 2.02 & - \\
\hline WA-TOL (inv) & 0.80 & 1.47 & -0.16 & 2.56 & - \\
\hline \multicolumn{6}{|l|}{ Classical } \\
\hline WA (cla) & 0.86 & 1.21 & -0.02 & 2.06 & - \\
\hline WA-TOL (cla) & 0.80 & 1.60 & -0.19 & 2.68 & - \\
\hline WA-PLS (1) & 0.86 & 1.19 & -0.05 & 2.05 & - \\
\hline WA-PLS (2) & 0.92 & 0.89 & -0.02 & 1.28 & 24.73 \\
\hline WA-PLS (3) & 0.93 & 0.86 & -0.02 & 0.82 & 3.31 \\
\hline WA-PLS (4) & 0.93 & 0.87 & -0.02 & 0.74 & -1.20 \\
\hline WA-PLS (5) & 0.92 & 0.90 & -0.03 & 0.78 & -3.06 \\
\hline \multicolumn{6}{|l|}{ c } \\
\hline \multicolumn{6}{|l|}{ Inverse } \\
\hline WA (inv) & 0.80 & 1.52 & -0.01 & 2.29 & - \\
\hline WA-TOL (inv) & 0.80 & 1.65 & -0.01 & 2.62 & - \\
\hline \multicolumn{6}{|l|}{ Classical } \\
\hline WA (cla) & 0.83 & 1.39 & -0.02 & 1.81 & - \\
\hline WA-TOL (cla) & 0.84 & 1.44 & -0.02 & 1.39 & - \\
\hline WA-PLS (1) & 0.80 & 1.56 & 0.05 & 2.03 & - \\
\hline WA-PLS (2) & 0.89 & 1.14 & -0.01 & 1.16 & 26.88 \\
\hline WA-PLS (3) & 0.90 & 1.10 & 0.03 & 1.05 & 3.95 \\
\hline WA-PLS (4) & 0.89 & 1.15 & 0.02 & 1.01 & -4.95 \\
\hline WA-PLS (5) & 0.87 & 1.22 & 0.02 & 1.06 & -6.00 \\
\hline
\end{tabular}

\subsubsection{Chironomid-inferred continentality model}

The ordinations suggest that although there is a strong relationship between the distribution and abundance of chironomids and mean July air temperature, continentality is also an important factor. A chironomid-inferred continentality (C-IC) transfer function was constructed from a combined Norwegian-Russian dataset of 149 lakes. The 149 lakes, which include 120 taxa, were selected to ensure a range of continentality indices $(\mathrm{CI})$ for each temperature interval (see Section 4.5). Within this data-set Pearson product-moment correlation coefficients suggest $\mathrm{CI}$ is weakly correlated with mean July air temperature $(r=-0.11)$ and water depth $(r=-0.38)$, but very strongly correlated to longitude $(r=0.92)$ and mean January air temperature $(r=-0.98)$. Continentality increases with distance from the ocean (Atlantic and Arctic Oceans), but as the effect is dominated by the Atlantic Ocean this approximates to longitude in this data-set. $\mathrm{CI}$ is calculated from the annual temperature range (mean January-July temperatures). The extremely strong negative correlation to mean January air temperature results from the larger variation in January air temperatures than July temperatures within the data-set. However as the lakes in the training set are covered in ice and thermally insulated throughout the winter, coldest month temperatures are 

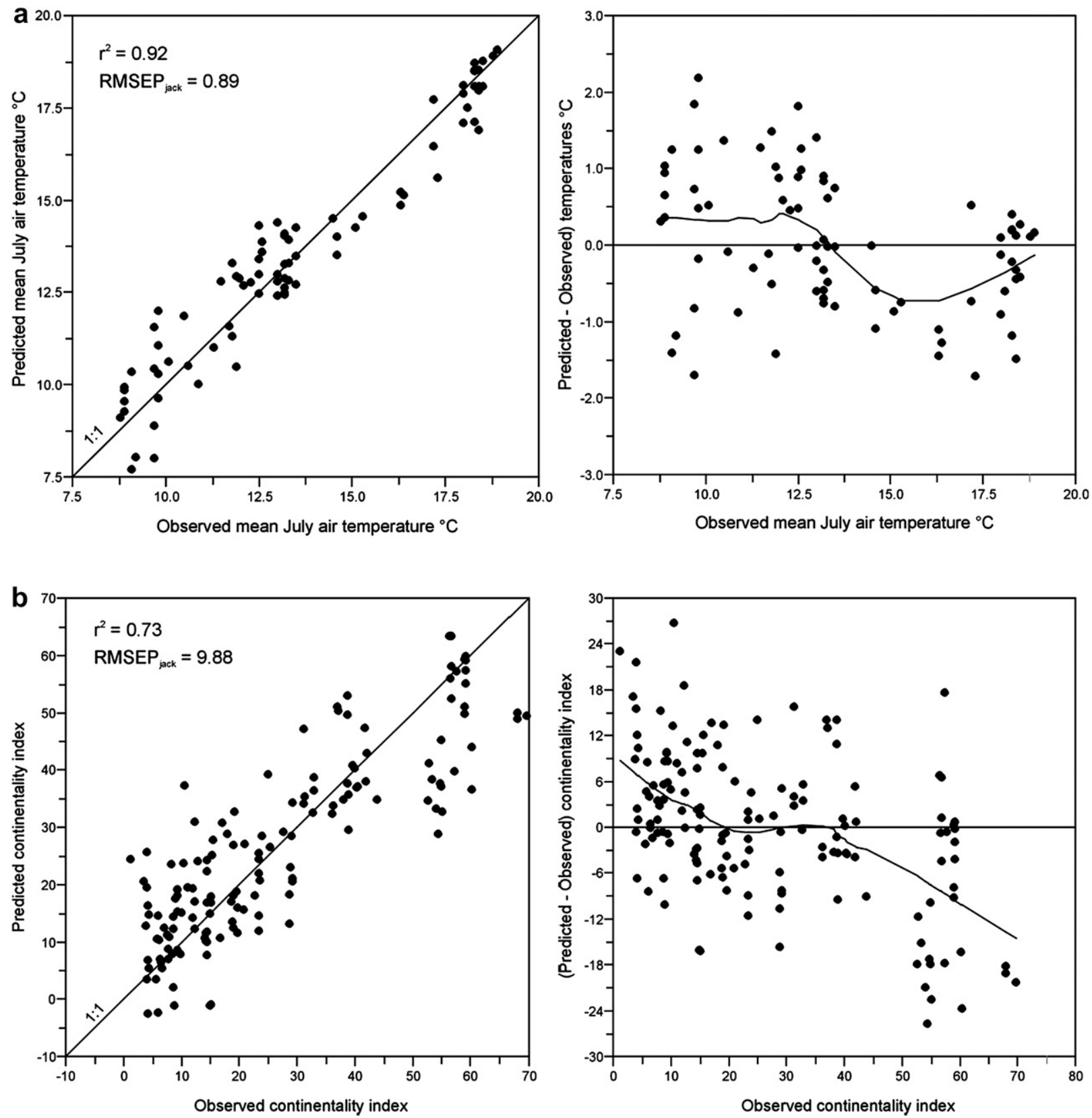

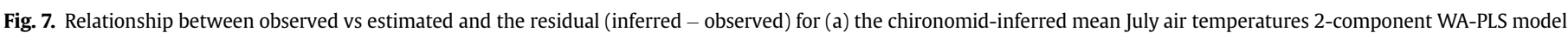
and (b) chironomid-inferred continentality 2-component WA-PLS model. Trends in residuals are highlighted with a LOESS smoother (span $=0.45$ ).

unlikely to have a direct impact on the chironomids. Variance partitioning by partial CCAs (Lepš and Šmilauer, 2003) showed that $31.6 \%$ of the total variation in the 149-lake species data can be explained by $\mathrm{CI}$ and mean July air temperature. Of this, $17.7 \%$ can be solely explained by the effects of continentality and $12.0 \%$ solely by July air temperature. The remaining $1.9 \%$ cannot be attributed solely to either environmental variable. Therefore the relationship with continentality in the 149-lake data-set appears to be independent of mean July air temperature.

The 2-component WA-PLS model represents the minimal adequate model (Birks, 1998) (Table 11) with a combination of high $r_{\text {jack }}^{2}(0.73)$ and low RMSEP jack (9.88 CI units). Additional components did not reduce the prediction error by more than $5 \%$ and were not included in the model (Birks, 1998). The model predicts reasonably well over the $\mathrm{CI}$ range $10-40$ but under-predicts above an index of 50, which is typical of locations east and south of the Ural Mountains (Fig. 7b). Although the use of C-IT models for reconstructing July air temperatures is well established, the use of a chironomid-inference model to reconstruct continentality has not been attempted before.

\subsection{C-IT and C-IC reconstructions from unnamed tundra lake VORK5}

July air temperature and $\mathrm{CI}$ are estimated from chironomid assemblages prepared from a $15 \mathrm{~cm}$ short core collected from an unnamed tundra lake in NE European Russia, codenamed VORK5. The ${ }^{210} \mathrm{~Pb}$ chronology suggested the core was deposited over the past 150 years, including the period from AD 1936 to present enabling comparison of inferred values with instrumental records. 
Table 11

Performance statistics for the chironomid-inferred continentality transfer function. The model with the statistically best performance is shown in bold. Max= maximum, inv $=$ inverse, cla $=$ classical, $\mathrm{TOL}=$ tolerance.

\begin{tabular}{|c|c|c|c|c|c|}
\hline Model & $r_{\text {jack }}^{2}$ & RMSEP $_{\text {jack }}$ & Mean bias ${ }_{\text {jack }}$ & Max bias $_{\text {jack }}$ & $\begin{array}{l}\text { Reduction } \\
\text { in prediction } \\
\text { error }(\%)\end{array}$ \\
\hline \multicolumn{6}{|l|}{ Inverse } \\
\hline WA (inv) & 0.65 & 11.16 & 0.06 & 25.39 & - \\
\hline WA-TOL (inv) & 0.57 & 12.50 & 0.06 & 20.72 & - \\
\hline \multicolumn{6}{|l|}{ Classical } \\
\hline WA (cla) & 0.65 & 12.69 & 0.07 & 18.49 & - \\
\hline WA-TOL (cla) & 0.58 & 15.00 & 0.05 & 14.65 & - \\
\hline WA-PLS (1) & 0.65 & 11.16 & -0.30 & 25.12 & - \\
\hline WA-PLS (2) & 0.73 & 9.88 & 0.08 & 19.26 & 11.53 \\
\hline WA-PLS (3) & 0.73 & 9.83 & 0.03 & 20.06 & 0.52 \\
\hline WA-PLS (4) & 0.71 & 10.23 & 0.04 & 19.97 & -4.07 \\
\hline WA-PLS (5) & 0.69 & 10.69 & 0.07 & 18.79 & -4.51 \\
\hline
\end{tabular}

\subsubsection{VORK5 chronology}

Unsupported ${ }^{210} \mathrm{~Pb}$ activities in VORK5 show a non-monotonic relationship with depth (Table 12 ) which indicates that changes have occurred in the initial ${ }^{210} \mathrm{~Pb}$ concentrations supplied to the sediment over time. This precludes the use of the Constant Initial Concentration (CIC) model (Appleby, 2001) and, therefore, ${ }^{210} \mathrm{~Pb}$ chronologies were calculated using the Constant Rate of Supply (CRS) dating model (Appleby and Oldfield, 1978). The raw CRS dating model places the AD 1963 layer at c. $6 \mathrm{~cm}$, above the AD 1963 layer suggested by the ${ }^{137} \mathrm{Cs}$ and ${ }^{241} \mathrm{Am}$ records. The final dates were calculated using the CRS model and corrected from the ${ }^{137} \mathrm{Cs} /{ }^{241} \mathrm{Am}$ records (Fig. 8).

\subsubsection{Biostratigraphy}

The diversity of the chironomid fauna in VORK5 is low and dominated by a small number of taxa (Fig. 9). Cold stenotherms such as H. lugubris-type (Cranston et al., 1983) and T. lugens-type (Brundin, 1956; Brodin, 1986) decline in abundance from the mid-twentieth century whilst thermophilic taxa such as C. mancus-type (Sæther, 1979; Brodin, 1986) increase in abundance. Corynocera ambigua increases from 3\% in AD 1850 to a peak of 37\% in AD 1962. Abundances of $C$. ambigua remain high but fluctuating until approximately AD 1990 before declining to late 19th century levels. Short-lived increases in C. ambigua in stratigraphic sequences are often associated with periods of environmental change within the lake.

\subsubsection{Reconstructions and comparison with instrumental data}

Despite the better performance statistics of the inference model based on the 81 Russian lake data-set the chironomid-inferred July air temperatures (C-IT) for VORK5 show little difference between

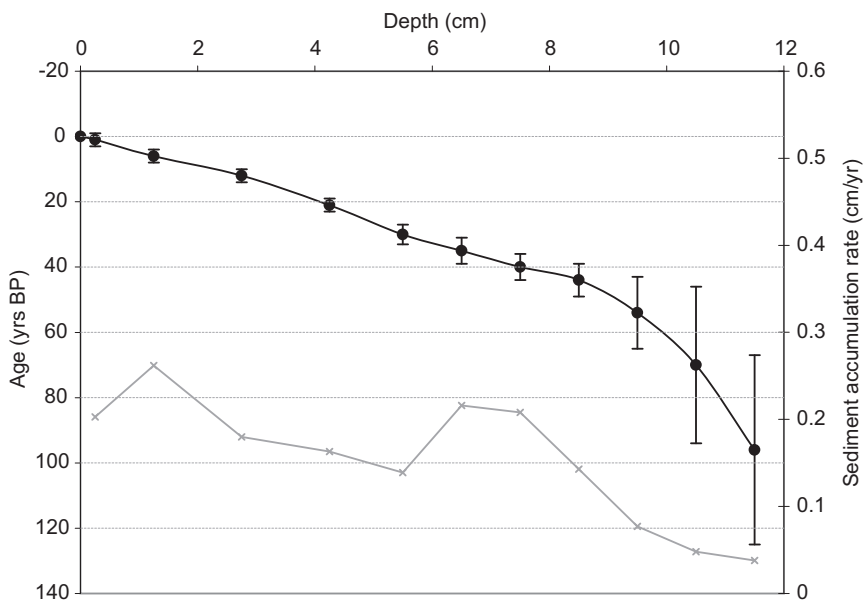

Fig. 8. Age-depth model and sediment accumulation rates for core VORK5 (sediment accumulation rates are shown in grey and ages in black with 2 SD error).

the reconstructions based on the 81-lake data-set and those based on the 100-lake data (Fig. 10a). Individual reconstructions vary by less than $0.6{ }^{\circ} \mathrm{C}$ and remain relatively stable at approximately $12{ }^{\circ} \mathrm{C}$ throughout the period covered by the instrumental record (AD 1938 to AD 2006), although the decline in cold stenotherms since AD 1940 would suggest the climate had warmed. Minor cool fluctuations occur in the AD 1950s and late AD 1990s when temperatures decline by approximately $0.8^{\circ} \mathrm{C}$, whilst temperatures warm by $0.4{ }^{\circ} \mathrm{C}$ during the AD 1960s. However all these oscillations are within the prediction error of the C-IT models. Chironomid-based July air temperature reconstructions based on the Norwegian data-set reconstruct approximately $1.0-2.7^{\circ} \mathrm{C}$ colder than the Russian models throughout the core. The variation between the reconstructions is greater than the prediction errors of the respective models.

Chironomid-inferred continentality reconstructions suggest the period from AD 1930s to AD 1970s was, in general, more continental than present $(\mathrm{CI}=50$, present-day $\mathrm{CI}=39)$ with the exception of a period of low $\mathrm{CI}$ in the $\mathrm{AD} 1940 \mathrm{~s}-50 \mathrm{~s}$. $\mathrm{CI}$ declined from 50 in AD 1971 to 32 in AD 1993, suggesting a more maritime climate. Over the last 25 years the continentality index has increased but shows greater inter-annual variation than earlier in the record.

Chironomid-inferred values are compared to instrumental records and the continentality index was calculated from the European Climate Assessment and Data-set records (Klein Tank et al., 2002) for Hoseda Hard $\left(67.08^{\circ} \mathrm{N}, 59.38^{\circ} \mathrm{E}\right)$, approximately $90 \mathrm{~km}$ south of VORK5 (Fig. 10). The higher sampling resolution and sediment accumulation rates towards the top of the core mean the

Table 12

Summary table showing the ${ }^{210} \mathrm{~Pb},{ }^{241} \mathrm{Am}$ and ${ }^{137} \mathrm{Cs}$ counting results, with respective errors, for the core VORK5.

\begin{tabular}{|c|c|c|c|c|c|c|c|}
\hline $\begin{array}{l}\text { Sample } \\
\text { depth }(\mathrm{cm})\end{array}$ & $\begin{array}{l}{ }^{210} \mathrm{~Pb} \text { activity } \\
\left(\mathrm{Bq} \mathrm{kg}^{-1}\right)\end{array}$ & $\begin{array}{l}\text { Counting error } \\
\left(\mathrm{Bq} \mathrm{kg}^{-1}\right)\end{array}$ & $\begin{array}{l}{ }^{210} \mathrm{~Pb} \text { unsupported } \\
\text { activity }\left(\mathrm{Bq} \mathrm{kg}{ }^{-1}\right)\end{array}$ & $\begin{array}{l}{ }^{137} \mathrm{Cs} \text { activity } \\
\left(\mathrm{Bq} \mathrm{kg}^{-1}\right)\end{array}$ & $\begin{array}{l}\text { Counting error } \\
\left(\mathrm{Bq} \mathrm{kg}^{-1}\right)\end{array}$ & $\begin{array}{l}{ }^{241} \mathrm{Am} \text { activity } \\
\left(\mathrm{Bq} \mathrm{kg}^{-1}\right)\end{array}$ & $\begin{array}{l}\text { Counting error } \\
\left(\mathrm{Bq} \mathrm{kg}^{-1}\right)\end{array}$ \\
\hline 0.25 & 223.54 & 32.85 & 175.1 & 18.83 & 4.3 & 0 & 0 \\
\hline 1.25 & 155.93 & 17.47 & 118.98 & 17.29 & 2.48 & 0 & 0 \\
\hline 2.75 & 167.67 & 19.84 & 137.76 & 15.16 & 2.71 & 0 & 0 \\
\hline 4.25 & 134.57 & 21.38 & 105.28 & 26.53 & 3.31 & 0 & 0 \\
\hline 5.5 & 115.76 & 13.79 & 85.71 & 38.61 & 2.41 & 0 & 0 \\
\hline 6.5 & 84.47 & 14.08 & 43.58 & 45.52 & 2.64 & 0 & 0 \\
\hline 7.5 & 70.03 & 13.67 & 37.17 & 65.5 & 2.68 & 0 & 0 \\
\hline 8.5 & 60.72 & 12.23 & 19.93 & 82.67 & 2.83 & 2.14 & 1.17 \\
\hline 9.5 & 47.51 & 10.9 & 20.66 & 58.37 & 2.05 & 0 & 0 \\
\hline 10.5 & 54.11 & 12.78 & 23.22 & 24.23 & 2.02 & 0 & 0 \\
\hline 11.5 & 47.82 & 10.87 & 13.23 & 6.56 & 1.52 & 0 & 0 \\
\hline 12.5 & 43.07 & 11.17 & 10.62 & 0 & 0 & 0 & 0 \\
\hline 13.5 & 23.17 & 10.43 & -3.43 & 0 & 0 & 0 & 0 \\
\hline
\end{tabular}




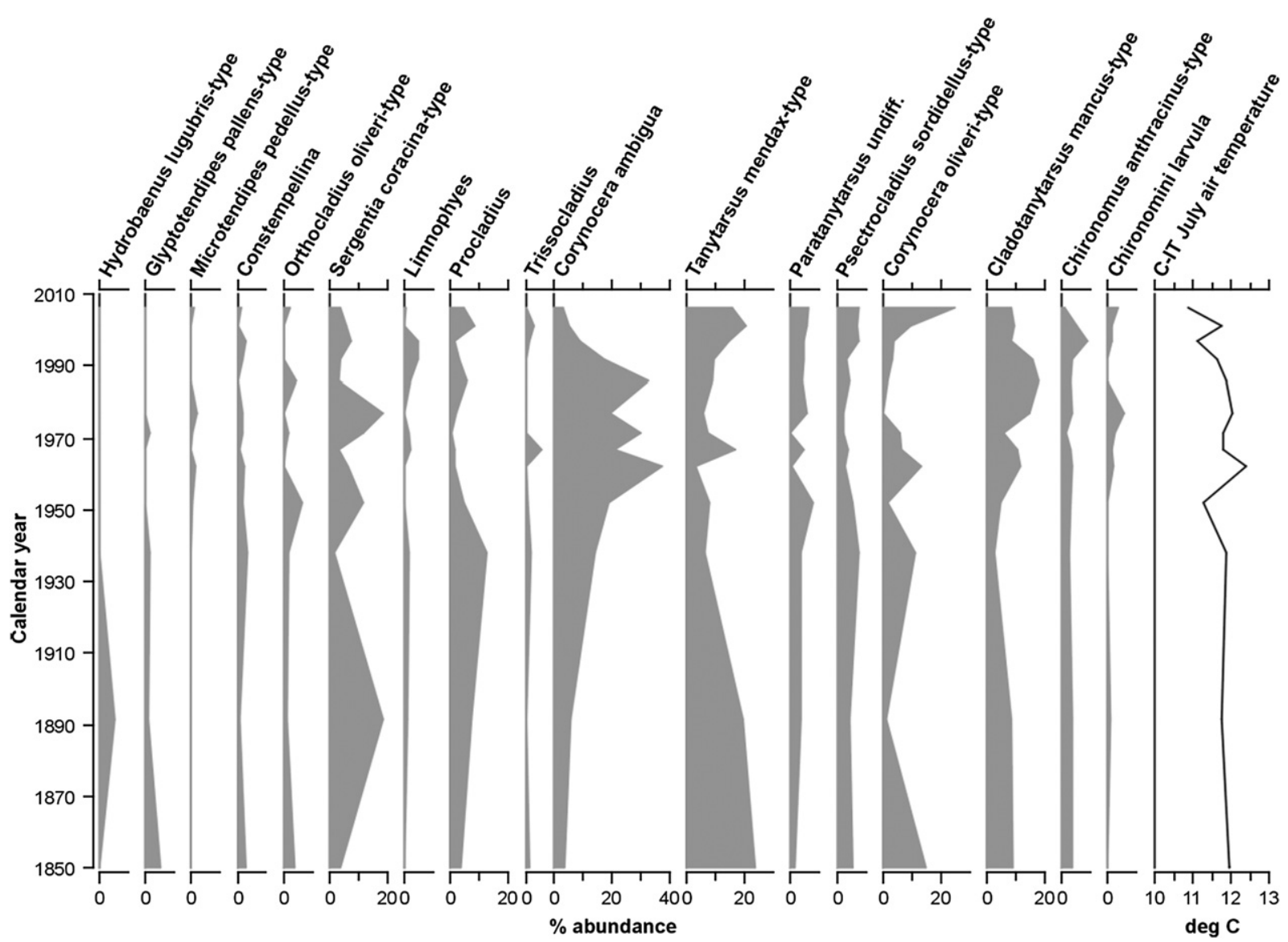

Fig. 9. Biostratigraphy of VORK5 showing taxa with $>5 \%$ abundance.

subsamples from 0 to $0.5 \mathrm{~cm}$ and $1.0-1.5 \mathrm{~cm}$ depth typically represent $2-3$ years accumulation of chironomid subfossils. The C-IT and C-IC estimates are in close agreement with the instrumental record for the mid-point, a single year, for these top two samples. Further down the core the lower sampling resolution and the greater uncertainty associated with the ${ }^{210} \mathrm{~Pb}$ dating means the subsamples represent an amalgamation of several years. The sample from 9 to $10 \mathrm{~cm}$ depth, for example, accumulated over approximately 14 years from AD 1945 to AD 1959. Therefore the values represent a general trend for the time interval. In general the chironomid-inferred temperatures are $0.4-2.5^{\circ} \mathrm{C}$ cooler and the $\mathrm{CI}$ values more continental than the instrumental records for Hoseda Hard which probably reflects the more northerly location of the lake. The chironomid-inferred July temperature reconstructions based on the Norwegian data-set are lower than those of the instrumental record. The Norwegian-based reconstruction also fails to reconstruct many of the decadal-scale fluctuations in the instrumental record. These results would suggest that the use of the Norwegian inference model would be inappropriate for this region of Russia.

On a decadal scale, the chironomid-inferred July air temperature (C-IT) reconstructions for VORK5 based on the Russian inference model show similar trends to the instrumental temperature over the period AD 1936-2006. Sample-specific prediction errors from the C-IT reconstructions are lower, $\pm 1.0^{\circ} \mathrm{C}$ than the high interannual variability in the instrumental record. Similarly the chironomid-inferred continentality (CI-IC) reconstructions from VORK5 show broad agreement to the instrument-derived record; both have a general trend to a more maritime climate over the last 25 years.

\section{Discussion}

The results suggest there is a strong relationship between chironomid distribution and abundance in north-west Russia and mean July air temperatures and continentality which dominate axes 1 and 2 respectively of the CCA plot (Fig. 3). These strong relationships also appear to persist over the wider geographical area of north-west Eurasia (i.e. Norway and north-west Russia) (Fig. 4). Of these, mean July air temperature is the most significant variable affecting chironomid distribution. The close relationship between chironomid assemblages and mean air temperature of the warmest month is well documented and has been used to develop chironomid-inferred temperature transfer functions in northern Eurasia (Lotter et al., 1997; Olander et al., 1999; Larocque et al., 2001; Luoto, 2008). The July air temperature gradient $\left(8.8-19.0^{\circ} \mathrm{C}\right)$ in the Russian data-set is comparable in length to the Swiss data-set $\left(6.6-17.3^{\circ} \mathrm{C}\right)$ (Lotter et al., 1997), but includes warmer temperatures than the Swedish (Larocque et al., 2001) or Norwegian data-sets $\left(7.0-14.7^{\circ} \mathrm{C}\right.$ and $3.5-16.0^{\circ} \mathrm{C}$ respectively). Water depth and mean annual precipitation were also statistically significant $(p \leq 0.05)$ in the Russian (Fig. 3) and Norwegian-Russian ordinations (Fig. 4). Although the range of water depths were similar in the Russian and Norwegian data-sets, the lakes in the 100-lake Russian data were skewed towards shallower depth (mean $=3.8 \mathrm{~m}$, median $=2.2 \mathrm{~m}$ ). Chironomids in shallow lakes are probably more prone to be directly affected by winter ice and by winter temperatures than larvae living in deeper lakes. Furthermore, a negative water balance, which affects the continental interior such as central Yakutia in the study area, may also lead to shallow lakes. These relationships could provide a potential problem for the continentality inference model. 

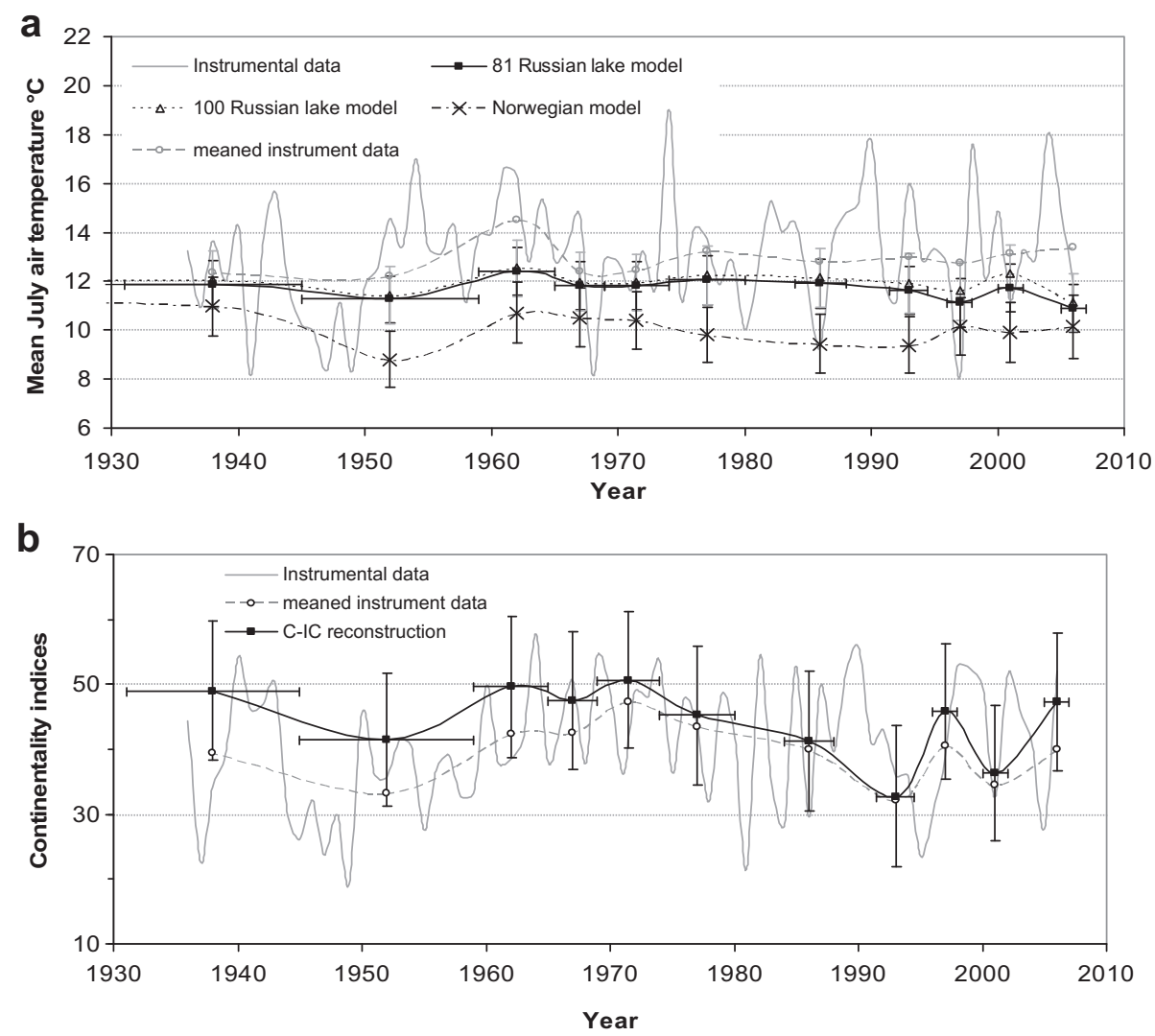

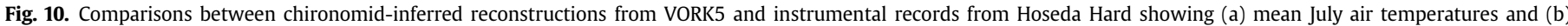

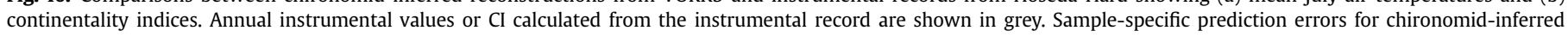

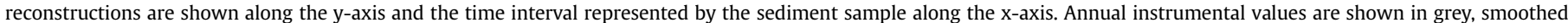

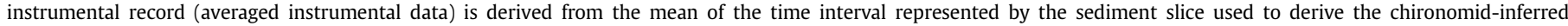
reconstruction to give a comparable temporal resolution.

However, in both the 257-lake Norwegian-Russian data-set and 149-lake subset the correlation coefficients between water depth and $\mathrm{CI}$ were $r=-0.40$ and $r=-0.38$, respectively, which suggests only a moderate to weak correlation between the variables.

Previous studies have suggested that total phosphorus (TP) (Brooks et al., 2001), dissolved oxygen (Quinlan and Smol, 2001b), organic carbon (Langdon et al., 2008) and chlorophyll ${ }_{\mathrm{a}}$ (Brodersen and Lindegaard, 1999) are potentially important environmental variables in influencing chironomid distribution and abundance. The data-sets used in this study were compiled by different researchers. Therefore the above variables were either not recorded or not measured consistently so could not be used in the ordinations. The relationship with any of these variables may be stronger than the observed relationship with continentality. However no data are available for comparison as no previous chironomid studies have included continentality as an environmental variable.

The 100-lake and 81-lake Russian data-sets were used to produce C-IT transfer functions as mean July air temperature was the most significant variable in explaining chironomid distribution in NW Russia (Table 5). The use of chironomid-inferred temperature (C-IT) models is well established (Brooks, 2006b; Heiri, 2006) and the performance of the C-IT models developed in the current study are similar to previously published models in terms of RMSEP, $r^{2}$ and maximum bias (Brooks, 2006a). Chironomid-inferred mean July air temperature reconstructions for a short core from a tundra lake, VORK5, varied by less than $0.6{ }^{\circ} \mathrm{C}$ between the reconstructions based on the 81-lake data-set and those based on the 100-lake data (Fig. 10a). Nineteen lakes with high conductivity, salinity or eutrophic status were removed from the 100-lake data- set to give values more similar to the Norwegian data-set. The deleted lakes were also from the warmest lakes $\left(18.0-19.0^{\circ} \mathrm{C}\right)$, therefore their deletion may have a more significant impact on reconstructions from warmer lakes than VORK5 where reconstructed temperatures varied between 10.9 and $12.5^{\circ} \mathrm{C}$. Chironomid-based July air temperature reconstructions based on the Norwegian data-set reconstruct approximately $1.0-2.7^{\circ} \mathrm{C}$ colder than the Russian models and are lower than the instrumental record. The Norwegian-based reconstructions also fail to reconstruct many of the decadal-scale fluctuations in July temperature seen in the instrumental record, which are reflected in the Russianbased reconstructions.

Additionally, a combined Russian-Norwegian training set was used to produce a C-IC transfer function as continentality indices are statistically significant in explaining chironomid distribution and abundance in these countries (Table 6). The development of the chironomid-inferred continentality (C-IC) model represents a novel approach to palaeoenvironmental reconstructions. However the relationship with $\mathrm{CI}$ and the performance of the C-IC transfer function is considerably weaker than the relationship with July air temperature, $r_{\text {jack }}^{2}$ is 0.92 for C-IT and 0.73 for C-IC. Gorczynski's continentality index $(\mathrm{CI})$ is calculated from the difference between summer and winter temperatures but also provides an 'estimate of the influence of the ocean on the local climate' (Grieser et al., 2006). The climate regime experienced by a lake in Norway with a July air temperature of approximately $14^{\circ} \mathrm{C}$ varies greatly from one in eastern Siberia with the same July temperature. For example Bergen $\left(60.38^{\circ} \mathrm{N}, 5.33^{\circ} \mathrm{E}, \mathrm{CI}=5.6\right.$, mean July temperature $\left.14.6^{\circ} \mathrm{C}\right)$ had an average of 317 days per year with air temperatures above $0^{\circ} \mathrm{C}$, 
between $\mathrm{AD} 1981-90$, and Olenyok $\left(68.5^{\circ} \mathrm{N}, 112.43^{\circ} \mathrm{E}, \mathrm{CI}=73.6\right.$, mean July temperature $14.0^{\circ} \mathrm{C}$ ) an average of 107 days per year above $0{ }^{\circ} \mathrm{C}$ (Royal Netherlands Meteorological Institute, 2009, http://climexp.knmi.nl/). Fig. 11 shows mean monthly air temperatures for Bergen and Olenyok. Although July air temperatures are similar, spring and autumn temperatures, the rates of spring warming and autumn cooling, and the duration of the warmest (summer) period vary considerably, in addition to the annual temperature range. Therefore, although continentality indices are calculated from the annual temperature range, continentality encapsulates more aspects of the climate regime than just the annual temperature range.

Chironomids in arctic environments generally overwinter in diapause or a quiescent state in frozen lakes in which water temperatures remain at or above $0^{\circ} \mathrm{C}$. Therefore it is unlikely they respond to winter temperature directly and may be responding to other climate variations. However, Larocque et al. (2001) showed that mean January air temperature also accounted for significant variation in chironomid assemblages in Sweden. Insects in the arctic are affected by the severity of the climate (cold temperatures, limited heat accumulation for growth), its seasonality (wide differences between summer and winter), short-term unpredictability (such as the potential for sudden changes in temperature even in summer) and variability (year-to-year changes in the factors governing development and survival) (Danks, 2004). Chironomids show a number of adaptations to arctic and subarctic environments. The number of generations per year is negatively correlated to latitude (Tokeshi, 1985) and extended life cycles of 2-7 years are common in many species at high latitudes (Welch, 1976; Butler, 1982) Chironomids, therefore, need to complete part of their life cycle during the summer and reach a resistant overwintering state before the onset of winter. The developmental rates of both eggs (Iwakuma, 1986) and larvae (Mackey, 1977; Edwards, 1986) are positively correlated to temperature, whereas daily growth rates appear to reach a maxima at a temperature optima (Storey, 1987; Hauer and Benke, 1991). This may ensure that larvae mature and pupate as fast as possible regardless of size. Variations in mean spring temperature, the rate of warming following ice-

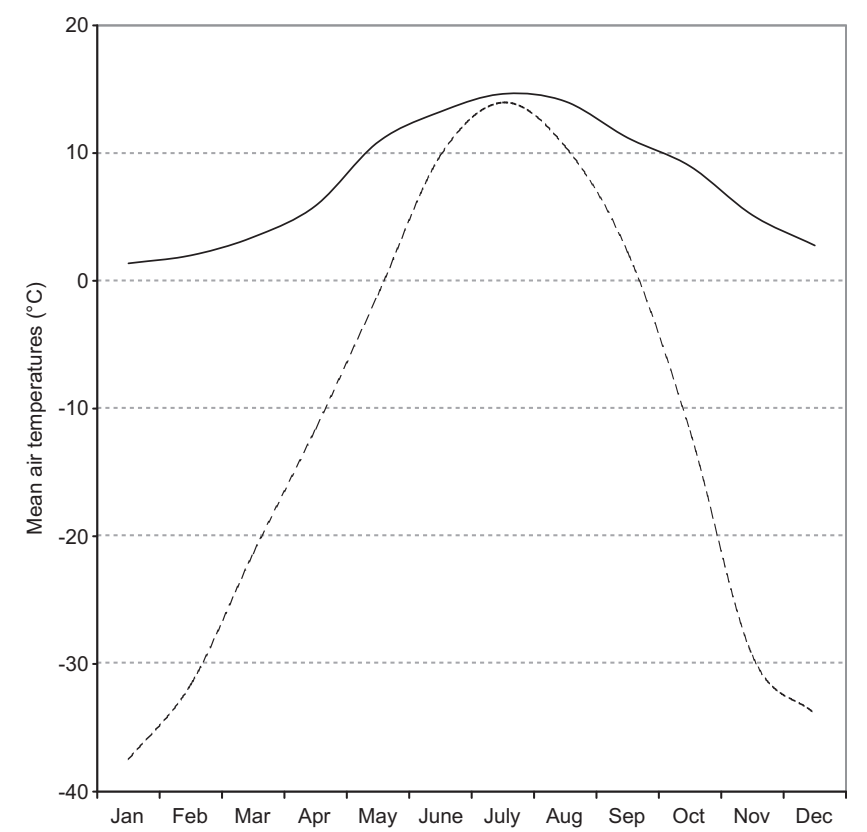

Fig. 11. Mean monthly air temperature for Bergen, $60.38^{\circ} \mathrm{N}, 5.33^{\circ} \mathrm{E}$, (solid line) and Olenyok, $68.5^{\circ} \mathrm{N}, 112.43^{\circ} \mathrm{E}$, (dashed line) between AD 1981-90 (Royal Netherlands Meteorological Institute, 2009, http://climexp.knmi.nl/). melt and the duration of the summer period due to differences in continentality may all affect the ability of species to complete part of their life cycle within the summer period. In areas with the continuous daylight of the polar summer the emergence of adults is governed by thresholds in water temperature (Danks and Oliver, 1972a). Data from four taxa, Corynoneura arctica, Stictochironomus sp., Micropsectra natvigi and Procladius culiciformis on Bathhurst and Ellesmere Islands, Canada suggest thresholds of $4-5{ }^{\circ} \mathrm{C}$ for pupation and $7{ }^{\circ} \mathrm{C}$ for pupal ecdysis (Danks, 1971; Danks and Oliver, 1972b). These thresholds, particularly for pupal ecdysis, are relatively high and often close to the lake water maximum temperature in high arctic lakes and for completion of pupation the temperatures need to be sustained for periods of up to 21 days. If these thresholds are not met then the species will not develop further that year. Therefore any change in the time interval above the threshold may influence the composition of the chironomid assemblage. The duration of lake ice may also affect the oxygen tension of the water column and surface sediments. Chironomid taxa vary in their oxy-regulatory capabilities (Brodersen et al., 2004) and prolonged ice cover may favour taxa able to tolerate low oxygen tensions. Further work is required to determine the relative importance of these mechanisms.

Taxa showing a statistically significant sigmoidal increasing response to continentality include cold stenothermic species such as Abiskomyia, H. conformis-type, T. lugens-type and C. oliveri-type (Brooks et al., 2007). Their increased occurrence in more continental climates ( $\mathrm{CI}$ above 40 ) suggests these species are ecologically or behaviourally adapted to completing part of their life cycle within the short continental summers and surviving the long icecovered winters. The majority of taxa demonstrating a statistically significant sigmoidal decreasing response to continentality are terrestrial, semi-terrestrial or associated with the splash zone or very shallow littoral zone. Most species of Smittia and the larvae of many Paraphaenocladius species are terrestrial (Cranston et al., 1983) while Pseudorthocladius (Strenzlke, 1950; Saether and Sublette, 1983), Synorthocladius (Cranston et al., 1983), Thienemanniella clavicornis-type (Cranston et al., 1983) and Thienemannimyia-type (Fittkau and Roback, 1983) occur in littoral, splash zones or streams. Although terrestrial habitats and the splash zone derive thermal insulation from the snow layer this can melt and refreeze throughout the winter period or be removed by strong winds which could leave chironomids in these environments vulnerable to cellular damage from repeated freeze-thawing. Therefore the decline in these species in more continental areas may reflect their inability to survive in these environments during the long cold winters rather than their failure to complete part of their life cycle within the short summer. The decline of stream dwelling taxa, such as Pseudorthocladius, Synorthocladius, Thienemanniella and Thienemannimyia, with increased continentality may reflect a decline in the number of stream-fed lakes and an increase in ground-water fed, thermokarst lakes across the continentality gradient.

Whereas increasing or decreasing sigmoidal responses may reflect an adaptation to, or tolerance of, differences in the length of the summer or intensity of the winter; the concept of a continentality optimum is more difficult to explain in an ecologically meaningful way. Taxa with unimodal responses (Table 9) may have a competitive advantage under certain climate regimes but are outcompeted by better adapted species in more extreme maritime or continental climates. Alternatively the taxa may be restricted geographically for reasons unrelated to the present-day climate such as past dispersal patterns. Nevertheless of the 15 taxa showing unimodal responses, 12 occur in both the Norwegian and Russian data-sets. Some of these taxa, such as $P$. triquetra-type have a Holarctic distribution and have also been found in Patagonian 
lakes (Massaferro and Brooks, 2002). Their widespread distribution suggests they may be restricted by local environmental factors, which may or may not be related to climate such as $\mathrm{pH}$. The remaining 3 taxa, Corynoneura type A, M. pallidula-type and Zavrelimyia were recorded in Norway only. This restricted distribution may reflect differences in biogeography, climate or the greater number of lakes in the Norwegian data-set. The eastern Palaearctic fauna includes a number of chironomid taxa which are not found in the western Palaearctic. Whilst this may be because climatic conditions are different in the eastern than western Palaearctic, a number of other insect groups have similar differences due to historical reasons such as glaciation, climate history and postglacial dispersal (Konstantinov et al., 2009).

The ordinations suggest that the distribution and abundance of chironomids in both the Norway and Russian data-sets are influenced by many of the same environmental variables. The TWINSPAN results indicate the composition of the faunal assemblages from the two data-sets are similar and many taxa show similar responses to July air temperature. These characteristics are sometimes used to justify the merging of training sets or the application of inference models to areas outside the geographical region used to compile the data. However, the species-temperature optima are consistently higher, with 1-2 exceptions, in the Russian lakes than the Norwegian data-set regardless of the statistical modelling technique used. The July temperature reconstruction of the short core VORK5 based on the Norwegian inference model was consistently lower than that based on the Russian C-IT model and the instrumental record. This suggests continentality may play a role in the chironomid response either directly through climate parameters such as the duration of the ice-free period or spring temperatures or indirectly through the occurrence of ground-water fed thermokarst or stream-fed lakes. Further work is needed to confirm the relationship between chironomid distribution and continentality, and possible mechanisms for the response. However if confirmed this would imply that inference models should be considered specific to a geographical region with a similar continentality regime. Application to sites tens to hundreds of kilometres outside the geographic area covered by the training set may be acceptable but the use of western European inference models to cores collected in central Siberia is unlikely to yield reliable reconstructions. However, the use of transfer functions from geographically distinct areas may be justified when fossil taxa are poorly represented in local training sets. For example, LarocqueTobler (2010) used North American and Swedish transfer functions to reconstruct July air temperatures at Egelsee, Switzerland as these data-sets had better representation of fossil taxa than the Swiss transfer function. The Swedish and North American-based reconstructions varied by up to $4{ }^{\circ} \mathrm{C}$, suggesting that whilst the general pattern of temperature change could be inferred using a transfer function from another region, estimates of temperature and the amplitude of change may be less reliable (Larocque-Tobler, 2010).

\section{Conclusions}

Numerical analysis of environmental variables and subfossil head capsules remains in the surface sediments of 100 lakes showed that mean July air temperature is the most significant variable explaining contemporary chironomid distribution and abundance in northern Russia. This has been shown to be an important environmental variable in a number of previous studies, leading to the development of chironomid-temperature transfer functions (e.g. in Northern Europe by Olander et al., 1999; Brooks and Birks, 2001; Larocque et al., 2001). The performance of the WA-PLS temperature inference in the present study, with RMSEP of $0.89{ }^{\circ} \mathrm{C}$ and $r^{2}$ of 0.92 , is comparable to these models. However, the Russian inference model improves the representation of a number of taxa, such as C. oliveri-type, Constempellina and Paracladius, which frequently occur in subfossil assemblages from arctic Russian lakes, but are poorly represented in European training sets. These are cold-adapted taxa and their absence from the training sets could lead to overestimations of July temperatures, using European inference models, in fossil samples where these taxa form a major component (for example see Andreev et al., 2005).

Ordinations also suggest that continentality, expressed as the $\mathrm{R}$ continentality index, is also a statistically significant variable influencing the distribution and abundance of chironomid assemblages and also the temperature optima of chironomid species. Temperature optima are consistently higher in the Russian data than in the Norwegian data which implies that chironomid-based temperature reconstructions for subfossil assemblages in Russian sediment samples using the Norwegian inference model, or visa versa, are likely to be reliable. This was confirmed by reconstructions of the Russian core, VORK5, based on the Norwegian C-IT inference model which underestimated July air temperatures at this lake and did not reconstruct decadal-scale oscillations in temperatures. Therefore inference models should only be considered applicable to sediment cores collected within the broad geographic source area of the training set and to areas with similar continentality regimes. The relationships with continentality enabled the development of chironomid-inference models to reconstruct continentality over north-east Eurasia and July temperature in north European Russia to central Siberia.

July air temperature and continentality reconstructions from an unnamed lake in north-east European Russia gave similar value and trends to instrumental data over the past 70 years. The ability of the Russian models to estimate accurately past climate suggests the Russian chironomid-July air temperature-inference model represents an improvement over the Swedish and Norwegian inference models, for chironomid-inferred temperature reconstructions in northern Russia. The continentality inference model represents the first attempt to reconstruct past continentality using chironomids. This has the potential to make a valuable contribution towards reconstructing past climates in Arctic environments where recent summer (June, July and August) warming appears dampened compared to other months (Hirschi et al., 2007). However further work is necessary to confirm the observed relationship with continentality and establish the biological mechanisms for the response. Continentality reconstructions over the Holocene where seasonal insolation has varied and the variations are known may help to elucidate the relationship.

\section{Acknowledgements}

The work by AS was funded by a NERC CASE studentship with the NHM (NER/S/A/2005/13227); additional funding was provided by CARBO-North funded under the EU Sixth Framework Programme Global Change and Ecosystems sub-programme (project number 036993). The sediment core was ${ }^{210} \mathrm{~Pb}$ dated by HY at the Bloomsbury Environmental Isotope Facility (BEIF) at UCL. Help with fieldwork was provided by Nadia Solovieva from UCL, London; Heikki Seppa and Sebastien Seboni from the University of Helsinki; Mikhail Brezin and Elena Tkacheva from Moscow Zoo and Vasily Ponomorov of the Komi Science Centre. In addition we would also like to thank the anonymous reviewers for their valuable comments on the manuscript.

\section{Appendix. Supplementary data}

Supplementary data associated with this article can be found, in the on-line version, at doi:10.1016/j.quascirev.2011.01.022. 


\section{References}

Andreev, A., Tarasov, P., Schwamborn, G., Ilyashuk, B., Ilyashuk, E., Bobrov, A. Klimanov, V., Rachold, V., Hubberten, H.-W., 2004. Holocene paleoenvironmental records from Nikolay Lake, Lena River Delta, Arctic Russia. Palaeogeography, Palaeoclimatology, Palaeoecology 209, 197-217.

Andreev, A., Tarasov, P., Ilyashuk, B., Ilyashuk, E., Cremer, H., Hermichen, W.-D., Wischer, F., Hubberten, H.-W., 2005. Holocene environmental history recorded in Lake Lyadhej-To sediments, Polar Urals, Russia. Palaeogeography, Palaeoclimatology, Palaeoecology 223, 181-203.

Appleby, P., Oldfield, F., 1978. The calculation of ${ }^{210} \mathrm{~Pb}$ dates assuming a constant rate of supply of unsupported ${ }^{210} \mathrm{~Pb}$ to the sediment. Catena $5,1-8$.

Appleby, P.G., Nolan, P.J., Gifford, D.W., Godfrey, M.J., Oldfield, F., Anderson, N.J., Battarbee, R.W., $1986 .{ }^{210} \mathrm{~Pb}$ dating by low background gamma counting. Hydrobiologia 141, 21-27.

Appleby, P.G., 2001. Chronostratigraphic techniques in recent sediments. In: Last, W.M., Smol, J.P. (Eds.), Tracking Environmental Change Using Lake Sediments. Kluwer Academic Publishers, Dordrecht, The Netherlands, pp. 171-203.

Barley, E.M., Walker, I.R., Kurek, J., Cwynar, L.C., Mathewes, R.W., Gajewski, K., Finney, B.P., 2006. A northwest North American training set: distribution of freshwater midges in relation to air temperature and lake depth. Journal of Paleolimnology 36, 295-314.

Bauch, H.A., Mueller-Lupp, T., Taldenkova, E., Spielhagen, R.F., Kassens, H Grootes, P.M., Thiede, J., Heinemeier, J., Petryashova, V.V., 2001. Chronology of the Holocene transgression at the North Siberian margin. Global and Planetary Change 31, 125-139.

Birks, H.J.B., 1998. Numerical tools in palaeolimnology - progress, potentialities and problems. Journal of Paleolimnology 20, 307-332.

Brodersen, K.A., Lindegaard, C., 1999. Classification, assessment and trophic reconstruction of Danish lakes using chironomids. Freshwater Biology 42, 143-157.

Brodersen, K.P., Pedersen, O., Lindegaard, C., Hamburger, K., 2004. Chironomids (Diptera) and oxy-regulatory capacity: an experimental approach to paleolimnological interpretation. Limnology and Oceanography 49, 1549-1559.

Brodin, Y.W., 1986. The postglacial history of Lake Flarken, southern Sweden, interpreted from subfossil insect remains. Internationale Revue der Gesamten Hydrobiologie 71, 371-432.

Brooks, S.J., Birks, H.J.B., 2000. Chironomid-inferred late-glacial and early-Holocene mean July air temperatures for Kråkenes Lake, western Norway. Journal of Paleolimnology 23, 77-89.

Brooks, S.J., Bennion, H., Birks, H.J.B., 2001. Tracing lake trophic history with a chironomid-total phosphorus inference model. Freshwater Biology 46 $513-533$.

Brooks, S.J., Birks, H.J.B., 2001. Chironomid-inferred air temperatures from Lateglacial and Holocene sites in north-west Europe: progress and problems. Quaternary Science Reviews 20, 1723-1741.

Brooks, S.J., 2003. Chironomidae (Insecta: Diptera). In: MacKay, A., Battarbee, R.W. Birks, H.J.B. (Eds.), Global Change in the Holocene. Arnold, London, pp. 328-341.

Brooks, S.J., 2006a. Fossil midges (Diptera: Chironomidae) as palaeoclimatic indicators for the Eurasian region. Quaternary Science Reviews 25, 1894-1910.

Brooks, S.J., 2006b. Chironomid records: Late Pleistocene of Europe. In: Elias, S.A. (Ed.), Encyclopedia of Quaternary Science. Elsevier Science, pp. 377-390.

Brooks, S.J., Langdon, P.G., Heiri, O., 2007. The Identification and Use of Palaearctic Chironomidae Larvae in Palaeoecology. Quaternary Research Association, London, $276 \mathrm{pp}$.

Brundin, L., 1956. Zur Systematik der Orthocladiinae (Dipt., Chironomidae). Report Institute of Freshwater Research, Drottningholm, pp. 5-185

Brundin, L, 1958. The bottom faunistical lake type system and its application to the southern hemisphere. Moreover a theory of glacial erosion as a factor of productivity in lakes and oceans. Verhandlungen der Interntionalen Vereinigung fur Theoretische und Angewandte Limnologie 13, 288-297.

Brundin, L., 1983. The larvae of Podonominae (Diptera: Chironomidae) of the Holarctic region - keys and diagnoses. In: Wiederholm, T. (Ed.), Chironomidae of the Holarctic Region. Keys and Diagnoses. Part 1-Larvae. Entomologica Scandinavica Supplement 19, 23-31. Lund, Sweden.

Butler, M.G., 1982. A 7-year life cycle for two Chironomus species in arctic Alaskan tundra ponds (Diptera: Chironomidae). Canadian Journal of Zoology 60, 58-70.

Comiso, J.C., 2003. Warming trends in the Arctic from clear sky satellite observations. Journal of Climate 16, 3498-3509.

Cranston, P.S., Oliver, D.R., Sæther, O.A., 1983. The larvae of the Orthocladiinae Diptera: Chironomidae) of the Holarctic region: keys and diagnoses. In: Wiederholm, T. (Ed.), Chironomidae of the Holarctic Region. Keys and Diagnoses. Part 1-Larvae. Entomologica Scandinavica Supplement 19, 149-291. Lund, Sweden.

Danks, H.V., 1971. Spring and early summer temperatures in a shallow arctic pond. Arctic 24, 113-123.

Danks, H.V., Oliver, D.R., 1972a. Diel periodicities of emergence of some high Arctic Chironomidae (Diptera). Canadian Entomologist 104, 903-916.

Danks, H.V., Oliver, D.R., 1972b. Seasonal emergence of some high Arctic Chironomidae (Diptera). Canadian Entomologist 104, 661-686.

Danks, H.V., 2004. Seasonal Adaptations in Arctic Insects. Integrative and Comparative Biology 44, 85-94.

Duff, K., Laing, T.E., Smol, J.P., Lean, D.R.S., 1998. Limnological characteristics of lakes located across arctic tree-line in northern Russia. Hydrobiologia 391, 205-222.
Edwards, D.H.D., 1986. Chironomidae (Diptera) of Australia. In: De Deckker, P., Williams, W.D. (Eds.), Limnology in Australia. CSIRO, Dordrecht, Melbourne, pp. 159-173.

Fittkau, E.J., Roback, S.S., 1983. The larvae of the Tanypodinae (Diptera: Chironomidae) of the Holarctic region - keys and diagnoses. In: Wiederholm, T. (Ed.), Chironomidae of the Holarctic Region. Keys and Diagnoses. Part 1-Larvae. Entomologica Scandinavica Supplement 19, 33-112. Lund, Sweden.

Giesecke, T.A.E.B., Chiverrell, R.C., Seppä, H., Ojala, A.E.K., Birks, H.J.B., 2008. Exploring Holocene continentality changes in Fennoscandia using present and past tree distributions. Quaternary Science Reviews 27, 1296-1308.

Gorczynski, W., 1920. Sur le calcul du degre du continentalisme et son application dans la climatologie. Geografiska Annaler 2, 324-331.

Grieser, J., Gommes, R., Cofield, S., Bernardi, M., 2006. Data Sources for FAO Worldmaps of Koeppen Climatologies and Climatic Net Primary Production. The Agromet Group, SDRN, Food and Agriculture Organization of the United Nations, Rome, Italy.

Hauer, F.R., Benke, A.C., 1991. Rapid growth of snag-dwelling chironomids in a blackwater river: the influence of temperature and discharge. Journal of the North American Benthological Society 10, 154-164.

Heiri, O., 2001. Holocene palaeolimnology of Swiss mountain lakes reconstructed using subfossil chironomid remains: past climate and prehistoric human impact on lake ecosystems. Ph.D. thesis, University of Bern, Bern, Switzerland, p. 113.

Heiri, O., 2004. Within-lake variability of subfossil chironomid assemblages in shallow Norwegian lakes. Journal of Paleolimnology 32, 67-84.

Heiri, O., 2006. Chironomid records: postglacial Europe. In: Elias, S.A. (Ed.), Encyclopedia of Quaternary Science. Elsevier, Amsterdam, pp. 390-398.

Hill, M.O., Šmilauer, P., 2005. TWINSPAN for Windows Version 2.3. Centre for Ecology and Hydrology \& University of South Bohemia., Huntingdon \& Ceske Budejovice.

Hirschi, J.J.-M., Sinha, B., Josey, S.A., 2007. Global warming and changes in continentality since 1948 . Weather $62,215-221$.

Hofmann, W., 1998. Cladocerans and chironomids as indicators of lake level changes in north temperate lakes. Journal of Paleolimnology 19, 55-62.

Ilyashuk, E., Ilyashuk, B., Hammarlund, D., Larocque, I., 2005. Holocene climatic and environmental changes inferred from midge (Diptera: Chironomidae, Chaoboridae, Ceratopogonidae) records at Lake Berkut, southern Kola Peninsula, Russia. The Holocene 15, 897-914.

IPCC, 2007. Summary for policymakers. In: Solomon, S., Qin, D., Manning, M., Chen, Z., Marquis, M., Averyt, K.B., Tignor, M., Miller, H.L. (Eds.), Climate Change 2007: The Physical Science Basis. Contribution of Working Group I to the Fourth Assessment Report of the Intergovernmental Panel on Climate Change. Cambridge University Press, Cambridge, UK and New York, NY, USA.

Iwakuma, T., 1986. Ecology and production of Tokunagayusurika akamusi (Tokunga) and Chironomus plumosus (L.) (Diptera: Chironomidae) in a shallow eutrophic lake. Ph.D. thesis, Kyushu University, Kyushu, Japan.

Juggins, S., 1994. Gaussian Logit Regression. Unpublished Computer Programme. Department of Geography, University of Newcastle, UK.

Juggins, S., 2005. C2 Version 1.4.3. Software for Ecological and Palaeoecological Data Analysis and Visualisation. Newcastle University, Newcastle upon Tyne, UK.

Kansanen, P.H., 1985. Assessment of pollution history from recent sediments in Lake Vanajavesi, southern Finland. II. Changes in Chironomidae, Chaoboridae and Ceratopogonidae (Diptera) fauna. Annales Zoologici Fennici 22, 57-90.

Klein Tank, A.M.G., Wijngaard, J.B., Können, G.P., Böhm, R., Demarée, G., Gocheva, A., Mileta, M., Pashiardis, S., Hejkrlik, L., Kern-Hansen, C., Heino, R., Bessemoulin, P., Müller-Westermeier, G., Tzanakou, M., Szalai, S., Pálsdóttir, T., Fitzferald, D., Rubin, S., Capaldo, M., Maugeri, M., Leitass, A., Bukantis, A., Aberfeld, R., Engelen, A.F.V.V., Forland, E., Mietus, M., Coelho, F., Mares, C., Razuvaev, V., Nieplova, E., Cegnar, T., López, J.A., Dahlström, B., Moberg, A., Kirchhofer, W., Ceylan, A., Pachaliuk, O., Alaxander, L.V., Petrovic, P., 2002. Daily dataset of 20th-century surface air temperature and precipitation series for the European Climate Assessment. International Journal of Climatology 22, 1441-1453.

Konstantinov, A.S., Korotyaev, B.A., Volkovitsh, M.G., 2009. Insect biodiversity in the Palearctic region. In: Foottit, R.G., Adler, P.H. (Eds.), Insect Biodiversity: Science and Society. Wiley-Blackwell, p. 656

Kumke, T., Ksenofontova, M., Pestryakova, L., Nazarova, L., Hubberten, H.-W., 2007. Limnological characteristics of lakes in the lowlands of Central Yakutia, Russia. Journal of Limnology 66, 40-53.

Langdon, P.G., Holmes, N., Caseldine, C.J., 2008. Environmental controls on modern chironomid faunas from NW Iceland and implications for reconstructing climate change. Journal of Paleolimnology 40, 273-293.

Larocque-Tobler, I., 2010. Reconstructing temperature at Engelsee, Switzerland using North American and Swedish chironomid transfer functions: potential and pitfalls. Journal of Paleolimnology 44, 243-251.

Larocque, I., Hall, R.I., Grahn, E., 2001. Chironomids as indicators of climate change: a 100-lake training set from a subarctic region of northern Sweden (Lapland). Journal of Paleolimnology 26, 307-322.

Lepš, J., Šmilauer, P., 2003. Multivariate Analysis of Ecological Data Using CANOCO. Cambridge University Press, Cambridge, 269 pp.

Lindegaard, C., 1992. Zoobenthos ecology of Thingvallavatn: vertical distribution, abundance, population, dynamics and production. Oikos 64, 257-304.

Lindegaard, C., 1995. Classification of water-bodies and pollution. In: Armitage, P., Cranston, P.S., Pinder, L.C.V. (Eds.), The Chironomidae: the Biology and Ecology of Non-biting Midges. Chapman and Hall, London, pp. 385-404.

Lindquist, S.J., 1999. The Timan-Pechora Basin Province of Northwest Arctic Russia: Domanik - Paleozoic Petroleum System. 
Lotter, A.F., Birks, H.J.B., Hofmann, W., Marchetto, A., 1997. Modern diatom, cladocera, chironomid, and chrysophyte cyst assemblages as quantitative indicators for the reconstruction of past environmental conditions in the Alps. I. Climate. Journal of Paleolimnology 18, 395-420.

Luoto, T.P., 2008. Subfossil Chironomidae (Insecta: Diptera) along a latitudinal gradient in Finland: development of a new temperature inference model. Journal of Quaternary Science 24, 150-158.

MacDonald, G.M., Kremenetski, C.V., Velichko, A.A., Cwynar, L.C., Riding, R.T., Goleva, A.A., Andreev, A., Borisova, O.K., Edwards, T.W.D., Hammarlund, D. Szeicz, J.M., Forman, S.L., Gataullin, V., 2000. Holocene treeline history and climate change across northern Eurasia. Quaternary Research 53, 302-311.

Mackey, A.P., 1977. Trophic dependencies of some larval Chironomidae (Diptera) and fish species in the River Thames. Hydrobiologia 62, 241-247.

Makarchenko, E.A., Makarchenko, M.A., 1999. Chironomidae. In: Tsalolikhin, S.J. (Ed.), Key to Freshwater Invertebrates of Russia and Adjacent Lands. Zoological Institute RAS, St. Petersburg, pp. 210-295.

Massaferro, J.I., Brooks, S.J., 2002. Response of chironomids to Late Quaternary environmental change in the Taitao Peninsula, southern Chile. Journal of Quaternary Science 17, 101-111.

McClelland, J., Holmes, R.M., Peterson, B.J., Stieglitz, M., 2004. Increasing river discharge in the Eurasia Arctic: consideration of dams, permaforst thaw and fires as potential agents of change. Journal of Geophysical Research - Atmospheres 109, D18102.

Meshkova, V., 2002. Dependency of outbreaks distribution from insects-defoliators' seasonal development. In: McManus, M.L., Liebhold, A.M. (Eds.), Proceedings of the Ecology, Survey and Management of Forest Insects. USDA Forest Service, Kraków, Poland, pp. 52-60.

Moller Pillot, H.K.M., Buskens, R.F.M., 1990. De larven der Nederlandse Chironomidae. Autoecologie en verspreiding. Nederlandse Faunistische Medelelingen $1 \mathrm{c}, 1-87$.

Murphy, J., Riley, J., 1962. A modified single solution for the determination of phosphate in natural waters. Analytica Chimica Acta 27 31-29.

Nalvikin, D.V., 1973. The geology of the U.S.S.R.

Nazarova, L.B., Pestryakova, L.A., Ushnitskaya, L.A., Hubberten H., W., 2008 Chironomids (Diptera: Chironomidae) in Lakes of Central Yakutia and their indicative potential for paleoclimatic research. Contemporary Problems of Ecology 15, 141-150.

Oksanen, J., Minchin, P.R., 2002. Continuum theory revisited: what shape are species responses along ecological gradients? Ecological Modelling 157, 119-129.

Olander, H., Birks, H.J.B., Korhola, A., Blom, T., 1999. An expanded calibration model for inferring lakewater and air temperatures from fossil chironomid assemblages in northern Fennoscandia. The Holocene 9, 279-294.

Peterson, B.J., Holmes, R.M., McClelland, J., Vorosmarty, C.J., Lammers, R.B., Shiklomanov, A.I., Shiklomanov, I.A., Rahstorf, S., 2002. Increasing river discharge to the Arctic Ocean. Science 298, 2171-2173.

Pinder, L.C.V., Reiss, F., 1983. The larvae of Chironominae (Diptera: Chironomidae) of the Holarctic region - keys and diagnoses. In: Wiederholm, T. (Ed.), Chironomidae of the Holarctic Region. Keys and Diagnoses. Part 1-Larvae. Entomologica Scandinavica Supplement 19, 149-292. Lund, Sweden.

Porinchu, D.F., Cwynar, L.C., 2000. The distribution of freshwater Chironomidae (Insecta: Diptera) across the treeline near the lower Lena River, northeast Siberia. Arctic, Antarctic and Alpine Research 32, 429-437.

Quinlan, R., Smol, J.P., 2001a. Setting minimum head capsule abundance and taxa deletion criteria in chironomid-based inference models. Journal of Paleolimnology 26, 327-342.

Quinlan, R., Smol, J.P., 2001b. Chironomid-based inference models for estimating end-of-summer hypolimnetic oxygen from south-central Ontario shield lakes. Freshwater Biology 46, 1529-1551.

R Development Core Team, 2004. R: a language and environment for statistical computing. R Foundation for Statistical Computing, Vienna, Austria, ISBN 3 900051-00-3. http://www.R-project.org.

Racca, J.M.J., Wild, M., Birks, H.J.B., Prairie, Y.T., 2003. Separating wheat from chaff: diatom taxon selection using an artificial neural network pruning algorithm. Journal of Paleolimnology 29, 123-133.

Rawlins, M.A., Willmott, C.J., 2003. Winter air temperature change over the Terrestrial Arctic, 1961-1990. Arctic, Antarctic and Alpine Research 35, 530-537.
Renberg, I., 1991. The HON-Kajak sediment corer. Journal of Paleolimnology 6, 167-170.

Rieradevall, M., Brooks, S.J., 2001. An identification guide to subfossil Tanypodinae larvae (Insecta: Diptera: Chironomidae) based on cephalic setation. Journal of Paleolimnology 25, 81-99.

Rigor, I.G., Colony, R.L., Martin, S., 2000. Variations in surface air temperature observations in the Arctic, 1979-1997. Journal of Climate 13, 896-914.

Rudolf, B., Fuchs, T., Schneider, U., Meyer-Christoffer, A., 2003. Introduction of the Global Precipitation Climatology Centre (GPCC). Deutscher Wetterdienst, Offenbach a.M, 16 pp.

Sæther, O.A., 1979. Chironomid communities as water quality indicators. Holarctic Ecology 2, 65-74.

Saether, O.A., Sublette, J.E., 1983. A review of the genera Doithrix n. gen., Georthocladius Strenzke, Parachaetocladius Wülker, and Pseudorthocladius Goetghebuer (Diptera: Chironomidae: Orthocladiinae). Entomologica Scandinavica Supplement 20, 1-100.

Sarmaja-Korjonen, K., Kultti, S., Valiranta, M., Solovieva, N., 2003. Mid-Holocene palaeoclimatic and palaeohydrological conditions in northeastern European Russia: a multi-proxy study of Lake Vankavad. Journal of Paleolimnology 30 415-426.

Schmid, P.E., 1993. A Key to the Larval Chironomidae and Their Instars from Austrian Danube Region Streams and Rivers. Part 1. Diamesinae, Prodiamesinae and Orthocladininae. Federal Institute for Water Quality, Wien.

Smol, J.P., Wolfe, A.P., Birks, H.J.B., Douglas, M.S.V., Jones, V.J., Korhola, A., Pienitz, R. Ruhland, K., Sorvari, S., Antoniades, D., Brooks, S.J., Fallu, M.-A., Hughes, M. Keatley, B.E., Laing, T.E., Michelutti, N., Nazarova, L., Nyman, M., Paterson, A. Perren, B., Quinlan, R., Rautio, M., Saulnier-Talbot, E., Siitonen, S., Solovieva, N. Weckstrom, J., 2005. Climate-driven regime shifts in the biological communities of arctic lakes. PNAS 102, 4397-4402.

Solovieva, N., Jones, V.J., Appleby, P.G., Kondratenok, B.M., 2002. Extent, environmental impact and long-term trends in atmospheric contamination in the Usa basin of east-European Russian Arctic. Water, Air and Soil Pollution 139, 237-260.

Solovieva, N., Jones, V.J. Nazarova, L, Brooks, S.J., Birks, HJ.B, Grytnes, J.-A Appleby, P.G., Kauppila, T., Kondratenok, B., Renberg, I., Ponomarev, V., 2005 Palaeolimnological evidence for recent climatic change in lakes from the northern Urals, arctic Russia. Journal of Paleolimnology 33, 463-482.

Storey, A.W., 1987. Influence of temperature and food quality on the life history of an epiphytic chironomid. Entomologica Scandinavica Supplement 29, 339-347.

Strenzlke, K., 1950. Systematik, Morphologie und Ökologie der terrestrischen Chironomiden. Archiv für Hydrobiologie Supplement 18, 207-414.

ter Braak, C.J.F., Looman, C.W.N., 1986. Weighted averaging, logistic regression and the Gaussian response model. Vegetatio 65, 3-11.

ter Braak, C.J.F., Juggins, S., 1993. Weighted averaging partial least squares regression (WA-PLS): an improved method for reconstructing environmental variables from species assemblages. Hydrobiologia 269, 485-502.

ter Braak, C.J.F., Śmilauer, P., 2002. CANOCO Reference Manual and User's Guide to CANOCO for Windows: Software for Canonical Community Ordination Version 4.5. Microcomputer Power, Ithaca, New York.

Tokeshi, M., 1985. Life cycles and population dynamics. In: Armitage, P., Cranston, P.S., Pinder, L.C.V. (Eds.), The Chironomidae: Biology and Ecology of Non-biting Midges. Chapman and Hall, London, pp. 225-268.

von Humboldt, A., 1827. Über die Haupt-Ursachen der temperature-verschiedenheit auf dem Erdkörper. Abhandlungen der Königlichen Akademie der Wissenschaften zu Berlin, Physikalische Klasse, 295-316.

Walker, I.R., Smol, J.P., Engstrom, D.R., Birks, H.J.H., 1991. An assessment of Chironomidae as quantitative indicators of past climatic change. Canadian Journal of Fisheries and Aquatic Science 48, 975-987.

Welch, H.E., 1976. Ecology of Chironomidae (Diptera) in a polar pond. Journal of the Fisheries Research Board of Canada 33, 227-247.

Wiederholm, T., 1983. Chironomidae of the Holarctic. Keys and diagnoses. Part 1 Larvae. Entomologica Scandinavica Supplement 19, Lund, Sweden, 457 pp.

Wood, S., 2007. GAMs with GCV Smoothness Estimation and GAMMs by REML/PQL. The mgcv package. simon.wood@r-project.org.

Zolotukhin, V.V., Almukhamedov, A.I., 1988. Traps of the Siberian platform. In: MacDougall, J.D. (Ed.), Continental Flood Basalts. Kluwer Academic Publishers, Dordrecht, pp. 273-310. 